\title{
NO adsorption and thermal behavior on Pd surfaces. A detailed comparative study
}

\author{
R.D. Ramsier ${ }^{\text {a }}$, Q. Gao ${ }^{\text {a }}$, H. Neergaard Waltenburg ${ }^{\text {a }}$, K.-W. Lee ${ }^{\text {a }}$, O.W. Nooij ${ }^{\text {, }}$, \\ L. Lefferts ${ }^{\text {a }}$, J.T. Yates, Jr. ${ }^{\text {a,* }}$ \\ ${ }^{a}$ Department of Chemistry, University of Pittsburgh, Surface Science Center, Pittsburgh, PA 15260, USA \\ ${ }^{b}$ Department of Physics, Eindhoven University of Technology, Eindhoven, Netherlands
}

Received 26 January 1994; accepted for publication 28 July 1994

\begin{abstract}
The adsorption and thermal behavior of NO on 'flat' Pd(111) and 'stepped' Pd(112) surfaces has been investigated by temperature programmed desorption (TPD), high resolution electron energy loss spectroscopy (IIREELS), and electron stimulated desorption ion angular distribution (ESDIAD) techniques. NO is shown to molecularly adsorb on both $\operatorname{Pd}(111)$ and $\operatorname{Pd}(112)$ in the temperature range $100-373 \mathrm{~K}$. NO thermally desorbs predominantly inolecularly from $\operatorname{Pd}(111)$ near 500 $\mathrm{K}$ with an activation energy and pre-exponential factor of desorption which strongly depend on the initial NO surface coverage. In contrast, $\mathrm{NO}$ decomposes substantially on $\mathrm{Pd}(112)$ upon heating, with relatively large amounts of $\mathrm{N}_{2}$ and $\mathrm{N}_{2} \mathrm{O}$ desorbing ncar $500 \mathrm{~K}$, in addition to NO. The fractional amount of NO dissociation on Pd(112) during heating is observed to be a strong function of the initial NO surface coverage. HREELS results indicate that the thermal dissociation of NO on both $\mathrm{Pd}(111)$ and $\mathrm{Pd}(112)$ occurs upon annealing to $490 \mathrm{~K}$, forming surface-bound $\mathrm{O}$ on both surfaces. Evidence for the formation of sub-surface $\mathrm{O}$ via NO thermal dissociation is found only on $\mathrm{Pd}(112)$, and is verified by dissociative $\mathrm{O}_{2}$ adsorption experiments. Both surface-bound $O$ and sub-surface $O$ dissolve into the Pd bulk upon annealing of both surfaces to $550 \mathrm{~K}$. HREELS and ESDIAD data consistently indicate that NO preferentially adsorbs on the (111) terrace sites of $\operatorname{Pd}(112)$ at low coverages, filling the (001) step sites only at high coverage. This result was verified for adsorption temperatures in the range $100-373 \mathrm{~K}$. In addition, the thermal dissociation of $\mathrm{NO}$ on $\mathrm{Pd}(112)$ is most prevalent at low coverages, where only terrace sites are occupied by NO. Thus, by direct comparison to NO/Pd(111), this study shows that the presence of steps on the Pd(112) surface enhances the thermal dissociation of NO, but that adsorption at the step sites is not the criterion for this decomposition.
\end{abstract}

\section{Introduction}

A fundamentally important question in surface science which has yet to be answered in general is: What is the role of surface structure in controlling the surface chemistry of adsorbed molecules? This

\footnotetext{
* Corresponding author. Fax: +1 4126246003.
}

question was conceptually raised in the early writings of Taylor [1], who envisioned that there were certain sites on a solid surface which were preferentially involved in the thermal reactions of adsorbed species. Although a great deal of understanding about the details of surface chemistry has been developed in recent decades [2], it is still not possible to provide a general answer to the question posed above. To investigate this topic in detail, one can choose a 
specific adsorbate/substrate system and systematically vary the substrate surface structure, exposing the reactant molecule to different substrate crystal planes. This permits the extraction of detailed information regarding the role that surface structure plays in controlling chemical reactions.

Along these lines, the present study focuses on the behavior of nitric oxide (NO) adsorbed on two related Pd single crystal surfaces. It will be shown that NO adsorption $\left(100 \leqslant T_{\text {ads }} \leqslant 373 \mathrm{~K}\right)$ on the 'flat' $\operatorname{Pd}(111)$ surface is molecular, with the $\mathrm{N}-\mathrm{O}$ bond axis oriented along the $\langle 111\rangle$ surface normal, independent of surface coverage. Upon heating, NO reversibly desorbs from $\mathrm{Pd}(111)$ with minimal decomposition, exhibiting first-order desorption kinetics with a desorption activation energy and pre-exponential factor which strongly depend on the initial NO surface coverage. A slight amount of NO thermal dissociation upon heating to $\sim 490 \mathrm{~K}$ deposits small amounts of surface-bound $\mathrm{O}$ on $\mathrm{Pd}(111)$, which dissolves into the Pd bulk upon heating above $550 \mathrm{~K}$.

NO adsorption $\left(100 \leqslant T_{\text {ads }} \leqslant 373 \mathrm{~K}\right)$ on the 'stepped' $\operatorname{Pd}(112)$ surface $(\operatorname{Pd}(S)[3(111) \times(001)])$ will also be shown to be molecular. However, contrary to the behavior observed in other systems, NO preferentially adsorbs at low coverages on the (111) terrace sites of $\mathrm{Pd}(112)$. Only at high coverages are both terrace and step sites occupied by $\mathrm{NO}$ on $\operatorname{Pd}(112)$. Upon heating, $\mathrm{N}_{2}$ and $\mathrm{N}_{2} \mathrm{O}$, in addition to $\mathrm{NO}$, desorb from $\mathrm{NO} / \mathrm{Pd}(112)$ in much larger relative yields than observed for $\mathrm{NO} / \operatorname{Pd}(111)$. This result indicates that the thermal decomposition of NO on the stepped surface competes more successfully with NO thermal desorption, as compared to the flat surface. The fractional amount of NO dissociation on $\operatorname{Pd}(112)$ upon heating is largest at the lowest NO coverages, where only terrace sites are occupied by NO. Evidence will be presented for the formation of both surface-bound $O$ and sub-surface $O$ on Pd(112) following the thermal decomposition of NO. This oxygen diffuses into the Pd bulk at temperatures above $550 \mathrm{~K}$.

\section{Experimental}

Both of the stainless steel ultra-high vacuum (UHV) systems employed in this study operated at base pressures of $<1 \times 10^{-10}$ Torr. The first UHV chamber contained an ion sputtering gun, a flux calibrated microcapillary array beam doser [3-5], a cylindrical mirror analyzer (CMA) for Auger electron spectroscopy (AES), a quadrupole mass spectrometer (QMS) for temperature programmed desorption (TPD), and a combination low energy electron diffraction (LEED) and electron stimulated desorption ion angular distribution (ESDIAD) apparatus $[6,7]$. In addition, a second electron gun mounted in this system could be used to induce electron stimulated desorption (ESD) of positive ions from the NO-covered Pd surfaces, with transmission into the QMS (ionizer turned off) for mass identification.

All of the TPD data presented in this report were recorded in the first UHV chamber. The QMS ionizing energy was $70 \mathrm{eV}$, and a $-150 \mathrm{~V}$ bias was applied to the crystal during TPD to prevent possible ESD damage to adsorbed NO by stray electrons from the QMS. The heating rates employed for TPD were $4.0 \mathrm{~K} / \mathrm{s}(\mathrm{NO} / \mathrm{Pd}(111))$ and $2.0 \mathrm{~K} / \mathrm{s}(\mathrm{NO} / \mathrm{Pd}(112))$, with temperatures measured via a chromel-alumel thermocouple spot welded to the edge of the crystal.

The ESDIAD patterns presented in this work were acquired at $100 \mathrm{~K}$ in the first vacuum system with incident electron beam energies $\left(E_{\mathrm{j}}\right)$ in the $800-1000$ $\mathrm{eV}$ range. The electron beam currents $(I \approx 5 \mathrm{nA})$ were measured between the crystal and ground and are uncorrected for secondary electron yield. These small currents were deliberately chosen to minimize the ESD damage ( $<1 \%$, see the Appendix) to adsorbed NO and to avoid raising the crystal temperature significantly $(<1 \mathrm{~K})$ during ESDIAD data acquisition. The ESDIAD data were acquired under field-free conditions, with the crystal and the first grid of the detection optics grounded. The ESDIAD patterns were digitally stored as a $64 \times 64$ array and were processed by digital smoothing and subtraction of a large X-ray background signal [6,7].

The second UHV chamber housed an ion sputtering gun, a flux calibrated microcapillary array beam doser [3-5], a CMA for AES, a QMS for TPD, LEED optics, and a high resolution electron energy loss spectrometer (HREELS). The HREELS data presented in this study was acquired at $100 \mathrm{~K}$. The primary beam energy utilized for HREELS was $4.5 \mathrm{eV}$ and the full width at half maximum of the elastic peak was about $60 \mathrm{~cm}^{-1}$. Typical counting 
rates of $1 \times 10^{5}$ counts per second were measured for the HREELS elastic beam from the clean Pd surfaces, and the HREELS data have been digitally smoothed [8].

Both the $\mathrm{Pd}(111)$ and $\mathrm{Pd}(112)$ single crystals employed in this study were cut from the same high-purity boule, which was cylindrical in shape with a diameter $\sim 0.93 \mathrm{~cm}$. The crystal surfaces were mechanically polished to mirror finish and oriented within $0.5^{\circ}$ using Lauc X-ray diffraction. Once under UHV conditions, the Pd surfaces were cleaned by $1000 \mathrm{~K} \mathrm{Ar}^{+}$ion sputtering $\left(E_{\mathrm{i}}=2 \mathrm{keV}\right.$, $I=2 \mu \mathrm{A})$ in the presence of $\sim 4 \times 10^{-8}$ Torr of $\mathrm{O}_{2}$. This was followed by $1000 \mathrm{~K}$ annealing in $\sim 2 \times$ $10^{-7}$ Torr $\mathrm{O}_{2}$ and then flash annealing to $1200 \mathrm{~K}$ in vacuum before measurements were performed. This cleaning procedure was repeated, in whole or in part, until AES showed no evidence for the impurities S ( $<0.1$ at $\%), O(<0.5$ at\%), and $C$ [9-13]. Due to overlapping C(KLL) and Pd(MNN) AES features [9-13], the final test of surface cleanliness was the lack $\left(<0.01\right.$ monolayer (ML)) of $\mathrm{CO}$ and $\mathrm{CO}_{2}$ thermal desorption from the $\mathrm{Pd}$ surfaces following adsorption of oxygen at room temperature. LEED was then employed to verify the proper structure of the clean Pd surfaces.

Nitric oxide ( ${ }^{14}$ NO, Matheson, $99 \%$ pure) and ${ }^{15}$ NO (Cambridge Isotopes, 99\% isotopically pure) was transferred into individual glass bulbs attached to the gas-handling systems. Freeze-pump-thaw cycles were employed for purification, and pure white crystalline NO was observed in the storage bulbs at liquid nitrogen temperature. Line-of-sight dosing into the QMS was used to verify the purity of these gases. NO was introduced onto the crystals with flux calibrated beam dosers [3-5] housed in both vacuum chambers; uncertainties in the cross-calibration of the two dosers are within $10 \%$.

\section{Results}

\subsection{Temperature programmed desorption}

All of the TPD data presented here were acquired in the same UHV system following $300 \mathrm{~K}$ adsorption of NO on clean Pd(111) and Pd(112) surfaces. Isotopically labelled ${ }^{15}$ NO was employed for TPD (al- though not shown here for $\mathrm{Pd}(111)$ ) in order that the observed products of ${ }^{15} \mathrm{NO}$ dissociation $\left({ }^{15} \mathrm{~N}_{2}, 30\right.$ amu and ${ }^{15} \mathrm{~N}_{2} \mathrm{O}, 46$ amu) could be clearly distinguished from $\mathrm{CO}$ (28 amu) and $\mathrm{CO}_{2}$ (44 amu). These carbon-containing species were undetectable ( $<0.01 \mathrm{ML}$ ) during TPD of ${ }^{15} \mathrm{NO}$ from either clean $\mathrm{Pd}$ surface. Additionally, no desorption of $\mathrm{O}_{2}$ or $\mathrm{NO}_{2}$ was observed by TPD under any conditions from ${ }^{14} \mathrm{NO}$ or ${ }^{15} \mathrm{NO}$ adsorbed on either $\mathrm{Pd}(111)$ or $\operatorname{Pd}(112)$.

The 'relative yields' to be discussed are the ratios of the integrated TPD areas of the observed NO decomposition products, ${ }^{15} \mathrm{~N}_{2}$ and ${ }^{15} \mathrm{~N}_{2} \mathrm{O}$, to the corresponding area of the ${ }^{15}$ NO TPD spectrum acquired simultaneously by multiplexing the QMS. The integrated areas of the TPD spectra are reproducible to within $5 \%$, and the uncertainty in the relative yields is therefore considered to be $\pm 11 \%$. No corrections to the TPD areas (and therefore to the

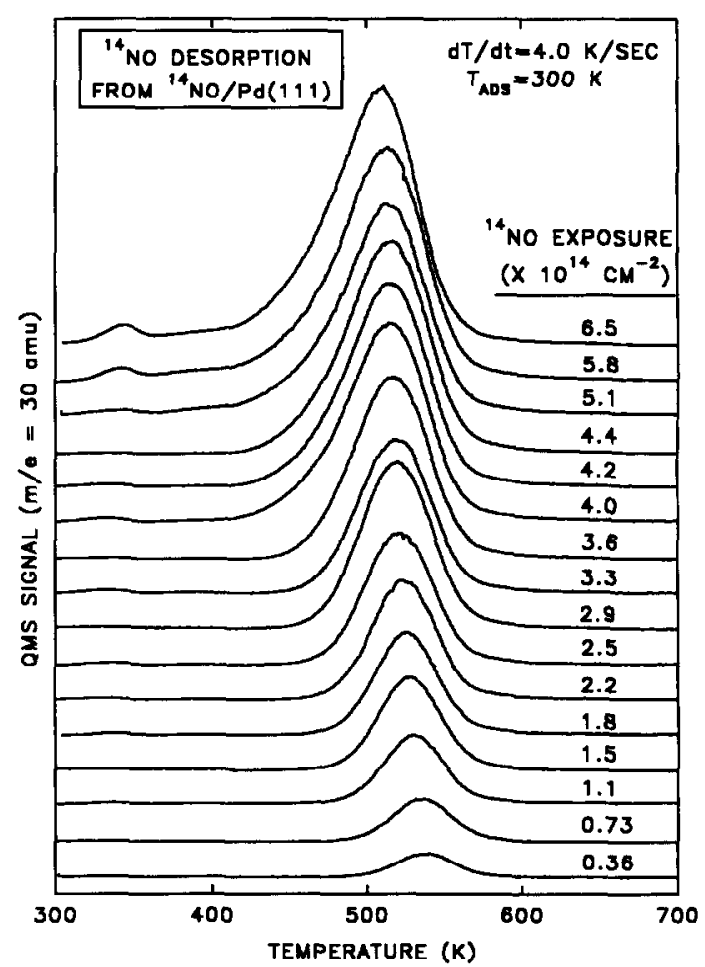

Fig. 1. Temperature programmed desorption spectra of ${ }^{14} \mathrm{NO}$ ( $m / e=30 \mathrm{amu}$ ) following adsorption of various amounts of ${ }^{14} \mathrm{NO}$ on $\mathrm{Pd}(111)$ at $300 \mathrm{~K}$. A heating rate of $4.0 \mathrm{~K} / \mathrm{s}$ was employed. 
relative yields) have been made for the different desorbing molecules due to variations in ionization probability, QMS throughput efficiency, QMS multiplier gain, chamber wall effects or chamber pumping speeds. The uncertainties associated with each of these factors makes such corrections questionable. Therefore, the relative yields of NO dissociation products observed during TPD are used comparatively for the two Pd crystals, and are not discussed in terms of absolute amounts of these species.

\subsection{1. $N O / P d(111)$}

Fig. 1 presents TPD spectra of ${ }^{14}$ NO (30 amu) from ${ }^{14} \mathrm{NO} / \mathrm{Pd}(111)$. Under all conditions tested, a relative yield $<0.005$ for the desorption of $\mathrm{N}_{2} \mathrm{O}$ was observed following $300 \mathrm{~K}$ adsorption of ${ }^{14} \mathrm{NO}$ or ${ }^{15} \mathrm{NO}$ on $\mathrm{Pd}(111)$ [14]. However, $\mathrm{N}_{2}$ thermal desorption was observed by TPD to approximately coincide with that of NO, with a small relative yield of 0.017 at high NO coverages [14]. These results indicate that only a very slight amount of NO dissociation

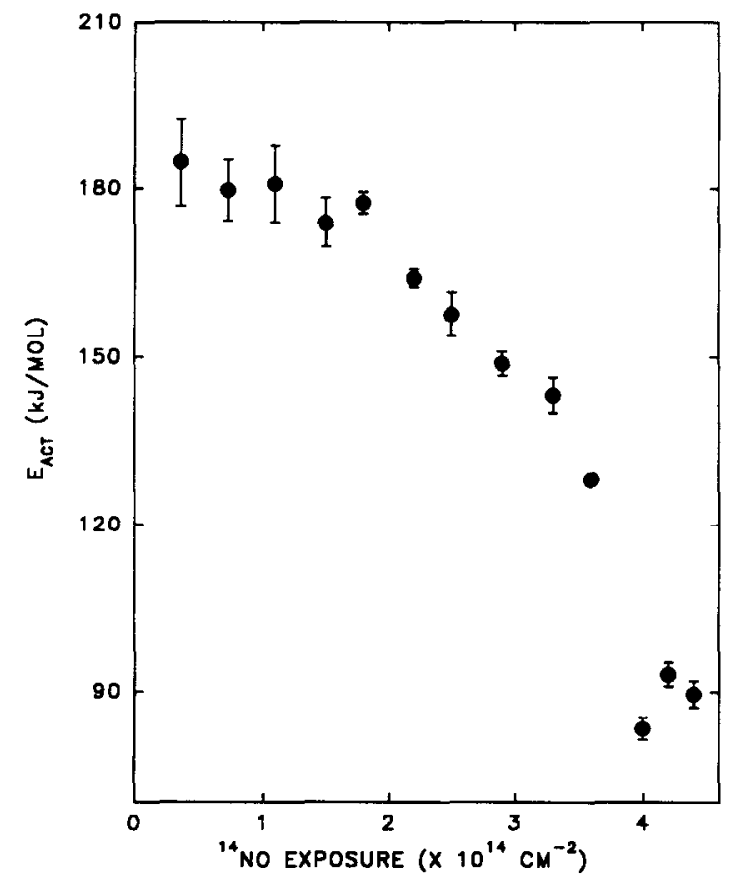

Fig. 2. The activation encrgy of first-order desorption of ${ }^{14} \mathrm{NO}$ from Pd(111) calculated from the spectra of Fig. 1 using the threshold temperature programmed desorption method. The decrease in $E_{\text {act }}$ as the ${ }^{14} \mathrm{NO}$ exposure increases indicates the presence of repulsive interactions between the adsorbed species.

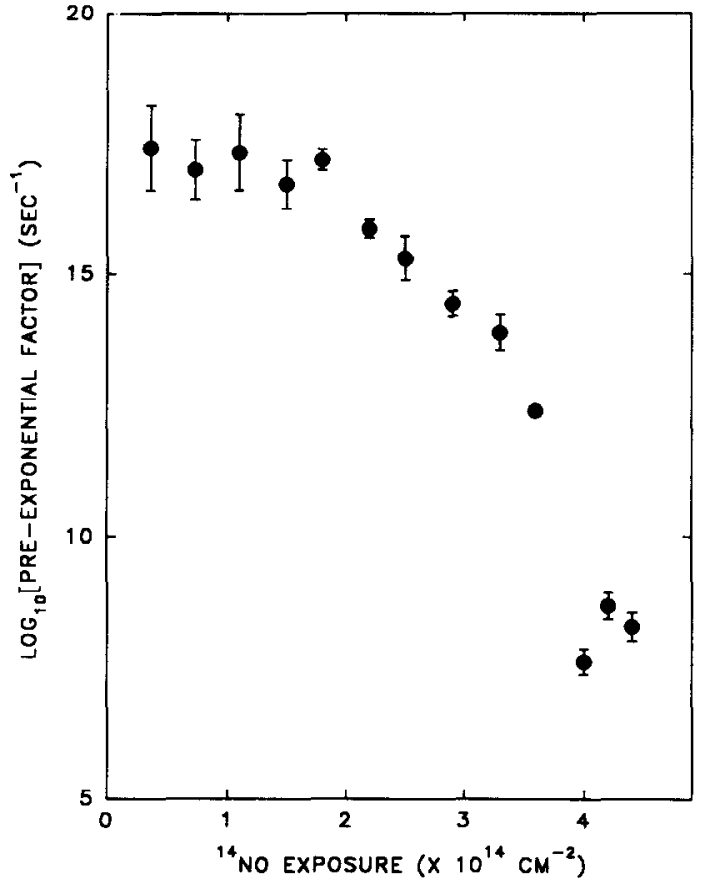

Fig. 3. Logarithmic plot of the pre-exponential factor of desorption of ${ }^{14}$ NO from Pd(111) calculated from the desorption spectra of Fig. 1. This data closely mirrors that shown for $E_{\text {act }}$ in Fig. 2, due to the 'compensation effect' often found in laterally interacting systems (see text).

occurs on $\operatorname{Pd}(111)$ during heating, possibly due to the presence of a small surface defect density.

It is seen in Fig. 1 that the thermal desorption of NO from Pd(111) occurs near $540 \mathrm{~K}$ at low coverage, shifting to near $510 \mathrm{~K}$ at higher coverages. The first-order kinetic parameters (activation energy of desorption, $E_{\text {act }}$, and pre-exponential factor) of NO thermal desorption from $\operatorname{Pd}(111)$ have been calculated from the data of Fig. 1, and are shown in Figs. 2 and 3 , respectively. The calculations were performed following the threshold temperature programmed desorption (TTPD) method [15], which relies on detailed analysis of the leading edge of a thermal desorption feature at various coverages. Figs. 2 and 3 resulted from such analysis of the first $5 \%$ (integrated area) of the lower 13 spectra of Fig. 1. Above an NO exposure of $4.4 \times 10^{14} \mathrm{~cm}^{2}$, low temperature NO desorption features $(300-400 \mathrm{~K})$ interfered with the linear background needed for TTPD analysis. 
As is evident in Figs. 2 and 3, both the activation energy and pre-exponential factor of NO thermal desorption from $\mathrm{Pd}(111)$ are strongly dependent on initial NO coverage. Both kinetic parameters have seemingly high values $\left(\sim 180 \mathrm{~kJ} / \mathrm{mol}\right.$ and $\sim 10^{17}$ $\mathrm{s}^{-1}$, respectively) at very low initial NO coverages, falling to $\sim 90 \mathrm{~kJ} / \mathrm{mol}$ and $\sim 10^{8} \mathrm{~s}^{-1}$ at the highest coverages. The error bars of Figs. 2 and 3 indicate the uncertainty in a least-squares fit of a straight line to the Arrhenius plots derived from the data of Fig. 1 via the TTPD method [15].

\subsection{2. $N O / P d(112)$}

Compared to NO/Pd(111), NO adsorbed on Pd(112) undergoes a significantly larger amount of decomposition upon heating [14]. TPD spectra acquired simultaneously following ${ }^{15} \mathrm{NO}$ adsorption on $\mathrm{Pd}(112)$ are shown in Fig. $4\left({ }^{15} \mathrm{NO}\right)$, Fig. $5\left({ }^{15} \mathrm{~N}_{2}\right)$, and Fig. $6\left({ }^{15} \mathrm{~N}_{2} \mathrm{O}\right)$. The relative scales of Figs. $4-6$ are indicated by the number of counts (an arbitrary unit) represented by a fixed height in each figure. As is evident from Figs. 4-6, the desorption yield of all

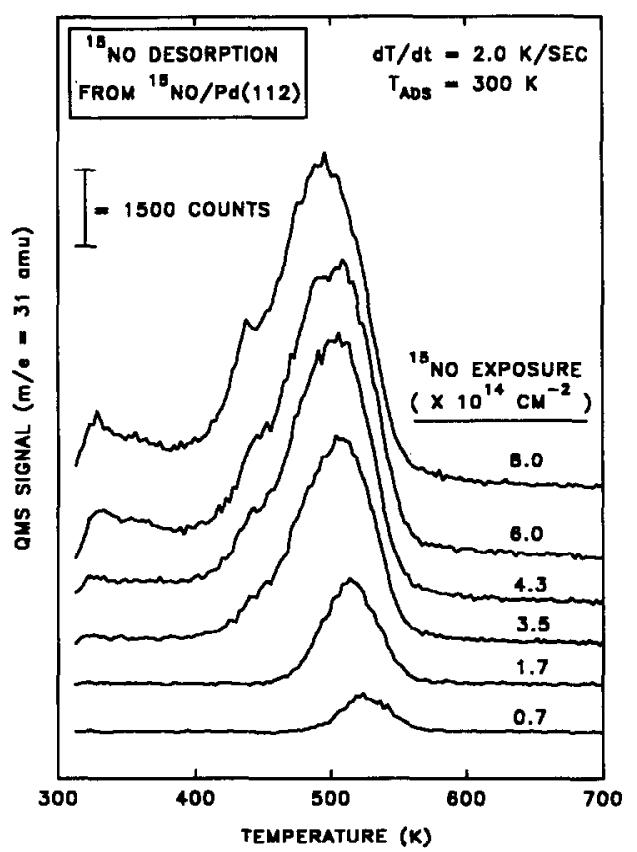

Fig. 4. Temperature programmed desorption spectra of ${ }^{15} \mathrm{NO}$ ( $m / e=31 \mathrm{amu}$ ) following adsorption of various amounts of ${ }^{15} \mathrm{NO}$ on $\operatorname{Pd}(112)$ at $300 \mathrm{~K}$. A heating rate of $2.0 \mathrm{~K} / \mathrm{s}$ was employed.

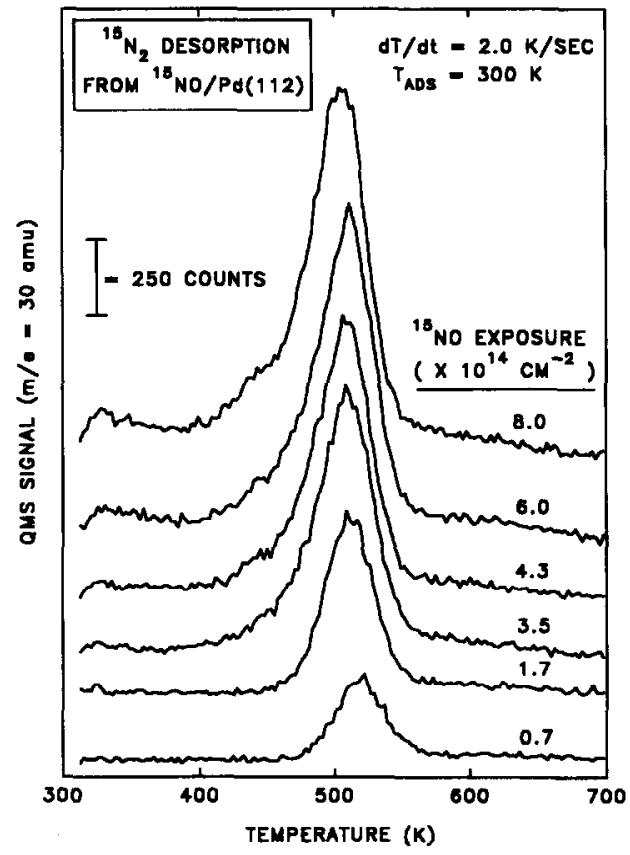

Fig. 5. Temperature programmed desorption spectra of ${ }^{15} \mathbf{N}_{2}$ ( $m / e=30 \mathrm{amu}$ ) following adsorption of various amounts of ${ }^{15} \mathrm{NO}$ on $\mathrm{Pd}(112)$ at $300 \mathrm{~K}$. These spectra indicate that ${ }^{15} \mathrm{NO}$ dissociates substantially on $\operatorname{Pd}(112)$ upon heating, and that the amount of ${ }^{15} \mathrm{~N}_{2}$ produced by this thermal decomposition increases with ${ }^{15} \mathrm{NO}$ exposure. A heating rate of $2.0 \mathrm{~K} / \mathrm{s}$ was employed.

three products increases monotonically with increased NO exposure, as determined by integration of the spectra [14].

The integrated areas of data like those of Figs. 4-6 have been used to calculate the relative TPD yields of ${ }^{15} \mathrm{~N}_{2}$ and ${ }^{15} \mathrm{~N}_{2} \mathrm{O}$ from ${ }^{15} \mathrm{NO} / \mathrm{Pd}(112)$. As seen in Fig. 7 , these relative yields are a strong function of NO coverage, with the largest fractional amount of NO decomposition occurring at the lowest NO exposures upon heating. Additionally, the relative yields of the products of $\mathrm{NO}$ dissociation $\left(\mathrm{N}_{2}\right.$ and $\mathrm{N}_{2} \mathrm{O}$ ) appear to saturate at the highest NO exposures in Fig. 7. The error bars of Fig. 7 represent the uncertainty in the relative yields discussed above $( \pm 11 \%)$, which are overshadowed by the size of the data points in some cases. No attempt has been made to analyze the TPD data from NO/ $\operatorname{Pd}(112)$ for kinetic parameters of desorption, since Fig. 7 indicates that NO thermal decomposition competes with NO thermal desorption in varying degrees as the NO coverage is changed. 


\subsection{High resolution electron energy loss spectroscopy}

All of the HREEL spectra presented in this report were recorded at $100 \mathrm{~K}$ in the same UHV chamber following either 100 or $373 \mathrm{~K}$ adsorption of ${ }^{14} \mathrm{NO}$ on $\operatorname{Pd}(111)$ and $\operatorname{Pd}(112)$. NO exposures (not absolute NO surface coverages) are stated and should not be used to estimate relative coverages due to possible differences in the NO sticking coefficient between the two surfaces at different adsorption temperatures and coverages. Stepwise annealing experiments following NO adsorption employed a temperature ramp of $2.0 \mathrm{~K} / \mathrm{s}$ to the desired temperature, followed by cooling to $100 \mathrm{~K}$ for HREELS data acquisition. During cooling and data acquisition, trace amounts $(<0.01 \mathrm{ML})$ of $\mathrm{CO}$ sometimes adsorbed on the Pd surfaces from the residual background gas of the UHV chamber. This adsorbed $\mathrm{CO}$ produces a vibrational feature near $1800 \mathrm{~cm}^{-1}$ in some of the HREEL

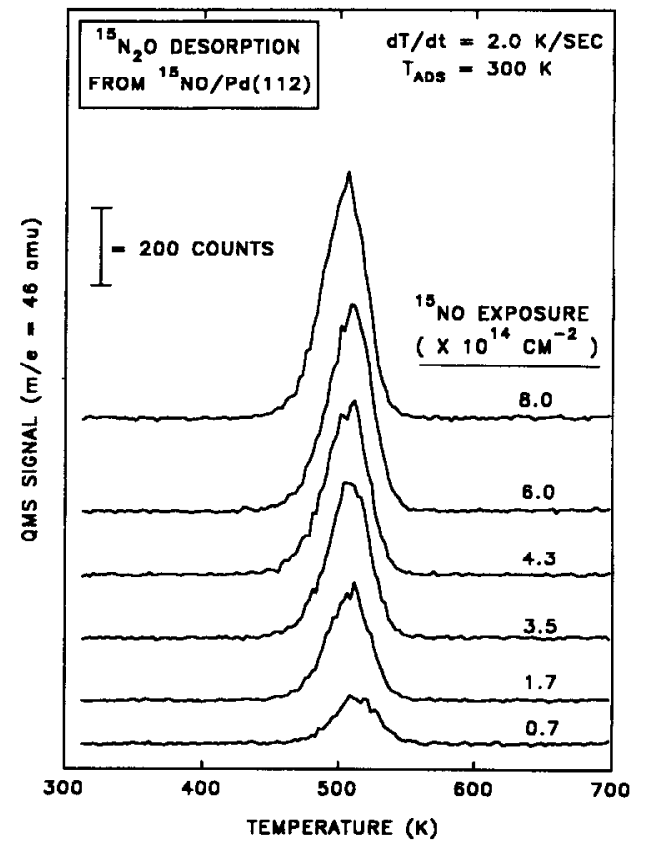

Fig. 6. Temperature programmed desorption spectra of ${ }^{15} \mathrm{~N}_{2} \mathrm{O}$ ( $m / e=46 \mathrm{amu}$ ) following adsorption of various amounts of ${ }^{15} \mathrm{NO}$ on $\mathrm{Pd}(112)$ at $300 \mathrm{~K}$. These spectra indicate that ${ }^{15} \mathrm{NO}$ dissociates substantially on $\operatorname{Pd}(112)$ upon heating, and that the amount of ${ }^{15} \mathrm{~N}_{2} \mathrm{O}$ produced by this thermal decomposition increases with ${ }^{15} \mathrm{NO}$ exposure. A heating rate of $2.0 \mathrm{~K} / \mathrm{s}$ was employed.

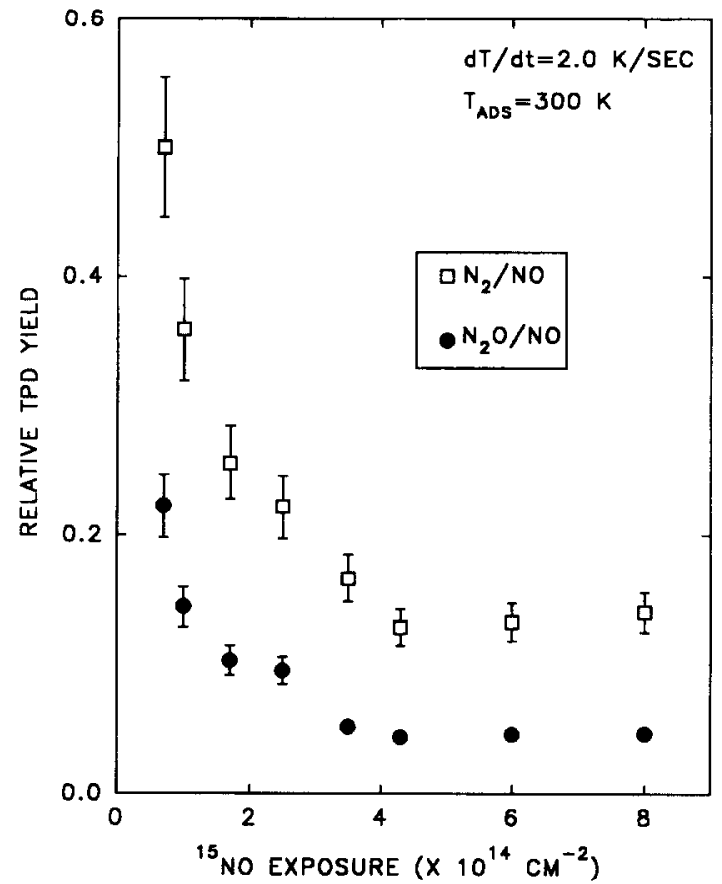

Fig. 7. Relative yields $( \pm 11 \%)$ of the products of NO thermal dissociation on $\operatorname{Pd}(112)$ calculated from the integrated yields of spectra like those of Figs. 4-6. The fractional amount of NO dissociation is largest at low coverage and saturates at high coverage, indicating that lateral interactions between the adsorbed species play a major role in determining the thermal surface chemistry. Correction for the sensitivity of the mass spectrometer to the three desorption products has not been made.

spectra. This $\mathrm{CO}$ does not affect the interpretation of the results, as verified by controlled $\mathrm{CO}+\mathrm{NO}$ coadsorption experiments.

\subsection{1. $100 \mathrm{~K}$ adsorption: $N O / P d(I I I)$ and $N O / P d(112)$}

Fig. 8 presents HREELS data acquired following adsorption at $100 \mathrm{~K}$ of $\mathrm{NO}$ on $\mathrm{Pd}(111)$ at various NO exposures. The spectra indicate that NO adsorption is molecular on Pd(111) under these conditions. The $\mathrm{N}-\mathrm{O}$ stretching mode $(\nu(\mathrm{N}-\mathrm{O}))$ at $1535 \mathrm{~cm}^{-1} \mathrm{ob}-$ served in the bottom spectrum of Fig. 8 shifts in frequency to $1600 \mathrm{~cm}^{-1}$ as the NO exposure is increased to $12 \times 10^{14} \mathrm{~cm}^{-2}$. At this NO exposure in Fig. 8, another $\nu(\mathrm{N}-\mathrm{O})$ mode is observed at 1750 $\mathrm{cm}^{-1}$ (shoulder), which then increases in relative intensity as the NO exposure is raised further. The most important point in Fig. 8 is that NO adsorbed 
on $\mathrm{Pd}(111)$ at $100 \mathrm{~K}$ exhibits only two well-resolved $\nu(\mathrm{N}-\mathrm{O})$ vibrational features at full coverage.

The HREEL spectra of Fig. 9 show that $100 \mathrm{~K}$ adsorption of $\mathrm{NO}$ on $\mathrm{Pd}(112)$ is also molecular. In the bottom spectrum of Fig. 9, a $\nu(\mathrm{N}-\mathrm{O})$ mode at $1522 \mathrm{~cm}^{-1}$ is observed, with a small shoulder at $\sim 1641 \mathrm{~cm}^{-1}$. Increasing the NO exposure to $6.5 \times$ $10^{14} \mathrm{~cm}^{-2}$ causes the lower frequency mode to shift to $1540 \mathrm{~cm}^{-1}$, while the $1645 \mathrm{~cm}^{-1} \nu(\mathrm{N}-\mathrm{O})$ mode increases in relative intensity. Finally, at high NO exposures, $\nu(\mathrm{N}-\mathrm{O})$ vibrational features at 1638 and $1738 \mathrm{~cm}^{-1}$ are seen in Fig. 9.

The most significant result of Fig. 9 is the presence of a $\nu(\mathrm{N}-\mathrm{O})$ mode near $1645 \mathrm{~cm}^{-1}$ at intermediate NO coverages. This band is not observed by HREELS from NO/Pd(111) under similar conditions (Fig. 8), and the $1645 \mathrm{~cm}^{-1}$ mode is interpreted as resulting from NO adsorbed at the (001) step sites of $\mathrm{Pd}(112)$. The frequencies of the dominant vibrational modes from $\mathrm{NO} / \mathrm{Pd}(111)$ and $\mathrm{NO} /$

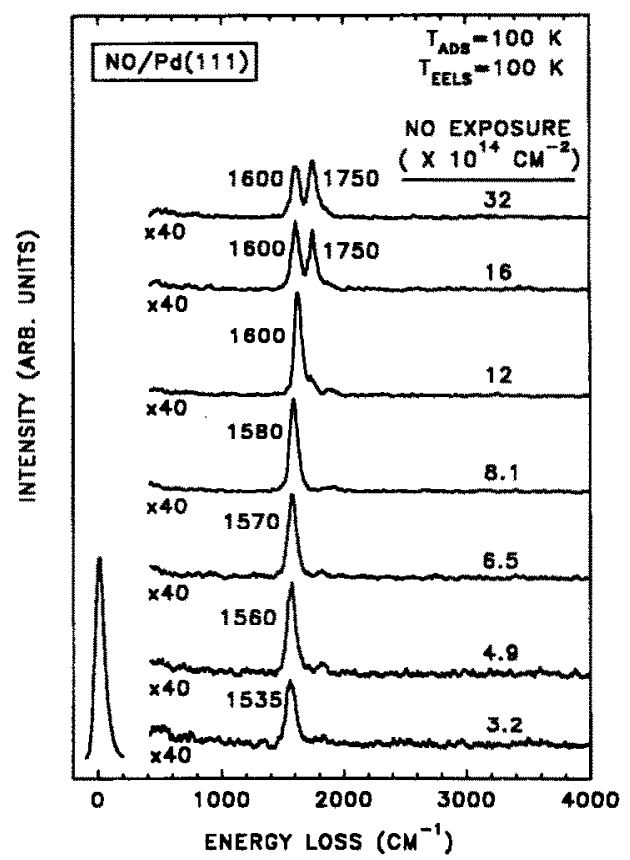

Fig. 8. High resolution electron energy loss spectra following adsorption of various amounts of NO on Pd(111) at $100 \mathrm{~K}$. These spectra indicate that NO adsorption is molecular on $\mathrm{Pd}(111)$ under these conditions. Note that only two, well-resolved $\nu(\mathrm{N}-\mathrm{O})$ modes are observed, shifting to higher frequency as the NO coverage is increased.

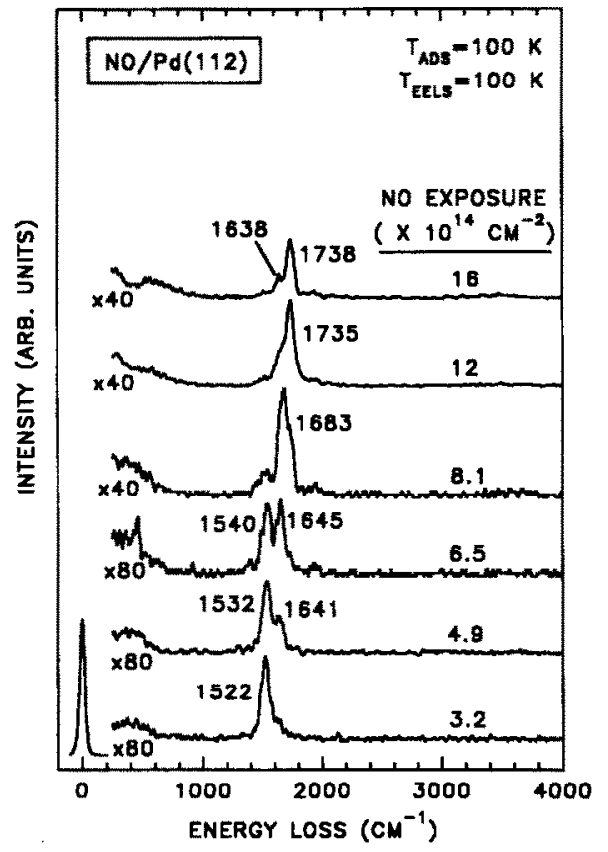

Fig. 9. High resolution electron energy loss spectra following adsorption of various amounts of $\mathrm{NO}$ on $\mathrm{Pd}(112)$ at $100 \mathrm{~K}$. These spectra indicate that $\mathrm{NO}$ adsorption is molecular on $\mathrm{Pd}(112)$ under these conditions. By comparison with the low coverage spectra of Fig. 8 , the $1522 \mathrm{~cm}^{-1} \nu(\mathrm{N}-\mathrm{O})$ band observed in the bottom spectrum is assigned to the vibrations of NO adsorbed at the (111) terrace sites of $\mathrm{Pd}(112)$. In addition, the $1645 \mathrm{~cm}^{-1} \nu(\mathrm{N}-\mathrm{O})$ mode observed here in the lower spectra, but not seen in Fig. 8 for Pd(111), is assigned to the vibrations of NO adsorbed at the (001) step sites of Pd(112).

$\operatorname{Pd}(112)$ at the lowest NO exposures are strikingly similar (1535 and $\left.1522 \mathrm{~cm}^{-1}\right)$ as shown in Figs. 8 and 9 , respectively. These results indicate that at low coverages, NO preferentially adsorbs on the (111) terrace sites of $\mathrm{Pd}(112)$ at $100 \mathrm{~K}$.

\subsection{2. $373 \mathrm{~K}$ adsorption: $N O / P d(111)$ and NO $/ P d(112)$}

The HREELS data of Fig. 10 were recorded following adsorption at $373 \mathrm{~K}$ of $\mathrm{NO}$ on $\mathrm{Pd}(111)$. As the exposure is increased, the $\nu(\mathrm{N}-\mathrm{O})$ mode at 1540 $\mathrm{cm}^{-1}$ (bottom spectrum) shifts in frequency to 1590 $\mathrm{cm}^{-1}$. This is the only $\nu(\mathrm{N}-\mathrm{O})$ mode observed by HREELS for NO adsorption at $373 \mathrm{~K}$ on $\mathrm{Pd}(111)$ under all conditions employed, which is the most important point to be stressed about Fig. 10. The observation of this $\nu(\mathrm{N}-\mathrm{O})$ mode in Fig. 10 indi- 
cates that NO is molecularly adsorbed on Pd(111) at $373 \mathrm{~K}$, and this mode is directly comparable to the low frequency $\mathrm{N}-\mathrm{O}$ mode observed in Fig. 8 for low coverage NO adsorption on $\mathrm{Pd}(111)$ at $100 \mathrm{~K}$.

NO adsorption at $373 \mathrm{~K}$ on $\mathrm{Pd}(112)$ produces vibrational spectra as shown in Fig. 11. The observation of a $1535 \mathrm{~cm}^{-1} \nu(\mathrm{N}-\mathrm{O})$ mode in Fig. 11 (bottom spectrum) indicates that $\mathrm{NO}$ adsorption is molecular on $\mathrm{Pd}(112)$ at $373 \mathrm{~K}$. As the NO exposure is raised, this mode shifts to $1550 \mathrm{~cm}^{-1}$, and another $\nu(\mathrm{N}-\mathrm{O})$ mode at $1655 \mathrm{~cm}^{-1}$ is resolved following exposure to $6.9 \times 10^{14} \mathrm{NO} / \mathrm{cm}^{2}$. At the highest $\mathrm{NO}$ exposures, a strong $1670 \mathrm{~cm}^{-1} \nu(\mathrm{N}-\mathrm{O})$ feature with a low frequency shoulder is observed (top spectrum) in Fig. 11. No other $\nu(\mathrm{N}-\mathrm{O})$ vibrational modes are observed from $\mathrm{NO} / \mathrm{Pd}(112)$ following adsorption at $373 \mathrm{~K}$ under any conditions employed.

It is clear by direct comparison of Fig. 9 to Fig. 11 that NO adsorption on $\mathrm{Pd}(112)$ initially proceeds via the same site-filling sequence for adsorption at either 100 or $373 \mathrm{~K}$. In addition, only one $\nu(\mathrm{N}-\mathrm{O})$ band is observed following NO adsorption at $373 \mathrm{~K}$

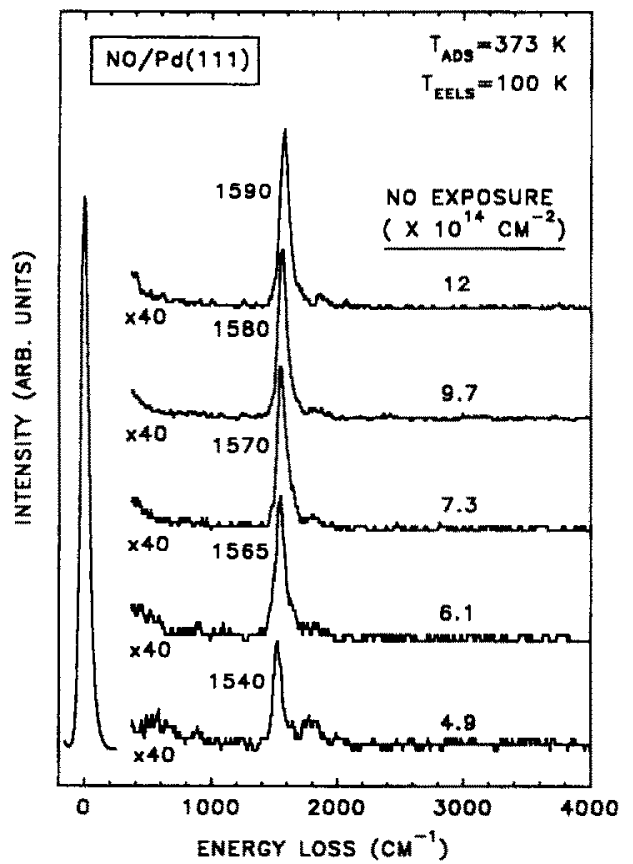

Fig. 10. High resolution electron energy loss spectra following adsorption of various amounts of $\mathrm{NO}$ on $\mathrm{Pd}(111)$ at $373 \mathrm{~K}$. These spectra indicate that NO adsorption is moleculat on $\mathrm{Pd}(111)$ under these conditions. Note that only one $\nu(\mathrm{N}-\mathrm{O})$ mode is observed.

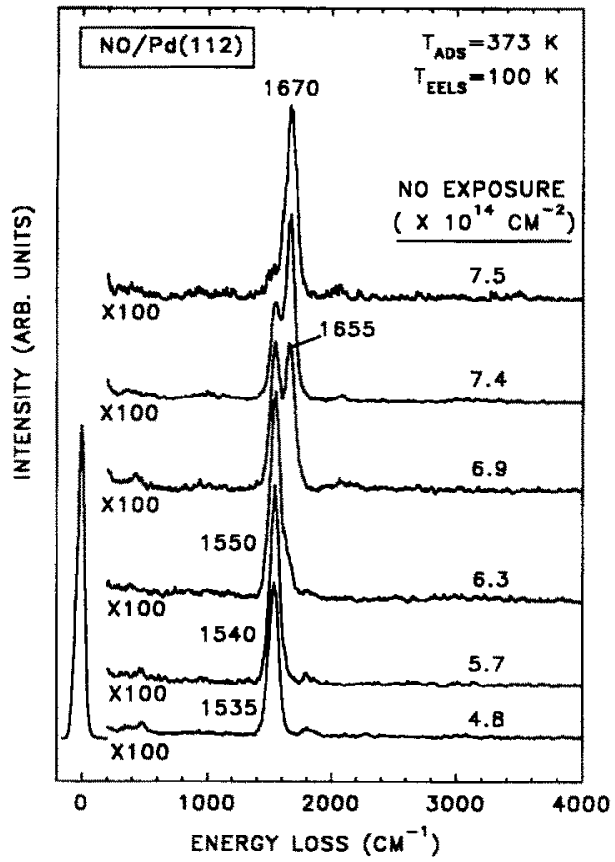

Fig. 11. High resolution electron energy loss spectra following adsorption of various amounts of $\mathrm{NO}$ on $\mathrm{Pd}(112)$ at $373 \mathrm{~K}$. These spectra indicate that $\mathrm{NO}$ adsorption is molecular on $\mathrm{Pd}(112)$ under these conditions. By comparison with the low coverage spectra of Fig. 10 for $\mathrm{Pd}(111)$, the $1535 \mathrm{~cm}^{-1} \nu(\mathrm{N}-\mathrm{O})$ band observed in the bottom spectra is assigned to the vibrations of NO adsorbed at the (111) terrace sites of $\mathrm{Pd}(112)$. In addition, the $1655 \mathrm{~cm}^{-1} \nu(\mathrm{N}-\mathrm{O})$ mode observed here in the upper spectra, but not seen in Fig. 10 for Pd(111), is assigned to the vibrations of NO adsorbed at the (001) step sites of $\mathrm{Pd}(112)$.

on $\mathrm{Pd}(111)$ (Fig. 10), whereas under similar conditions two $\nu(\mathrm{N}-\mathrm{O})$ modes are present in the vibrational spectra from $\mathrm{NO} / \mathrm{Pd}(112)$ (Fig. 11). Direct comparison of these two figures indicates that the $1655 \mathrm{~cm}^{-1}$ feature in Fig. 11 results from $\nu(\mathrm{N}-\mathrm{O})$ vibrations of NO adsorbed at the (001) step sites of $\operatorname{Pd}(112)$. Thus HREELS indicates that the low coverage adsorption $\left(100 \leqslant T_{\text {ads }} \leqslant 373 \mathrm{~K}\right)$ of NO occurs preferentially on the (111) terraces of $\operatorname{Pd}(112)$, with both (111) terrace sites and (001) step sites becoming occupied at higher NO coverages.

\subsubsection{Thermal behavior: NO $/ P d(111)$ and $N O / P d(112)$}

The HREEL spectra of Fig. 12 illustrate the effect of heating an NO-saturated $\mathrm{Pd}(111)$ surface following NO exposure at $373 \mathrm{~K}$. The decrease in fre- 
quency of the $1585 \mathrm{~cm}^{1} \nu(\mathrm{N}-\mathrm{O})$ mode (bottom spectrum) in Fig. 12 with increasing annealing temperature is due to the removal of surface-bound NO via thermal desorption (i.e. the lower the NO coverage, the lower the $\nu(\mathrm{N}-\mathrm{O})$ frequency). A similar shift of this $\nu(\mathrm{N}-\mathrm{O})$ frequency with changing coverage is seen in Fig. 10.

The most significant change in the spectra of Fig. 12 is the appearance of a $\nu(\mathrm{Pd}-\mathrm{O})$ mode at 525 $\mathrm{cm}^{-1}$ with a shoulder near $700 \mathrm{~cm}^{-1}$ upon heating above $490 \mathrm{~K}$. This observation indicates that a small amount of NO dissociates upon heating above 490 $K$, leaving $O(a)$ on the $\operatorname{Pd}(111)$ surface. This is consistent with the TPD results discussed in Section 3.1.1, where small relative yields of $\mathrm{N}_{2}$ but no appreciable desorption of oxygen-containing species was observed from $\mathrm{NO} / \mathrm{Pd}(111)$. This surface-bound $\mathrm{O}$ on $\mathrm{Pd}(111)$ diffuses into the Pd bulk at temperatures above $550 \mathrm{~K}$, as evidenced by the disappear-

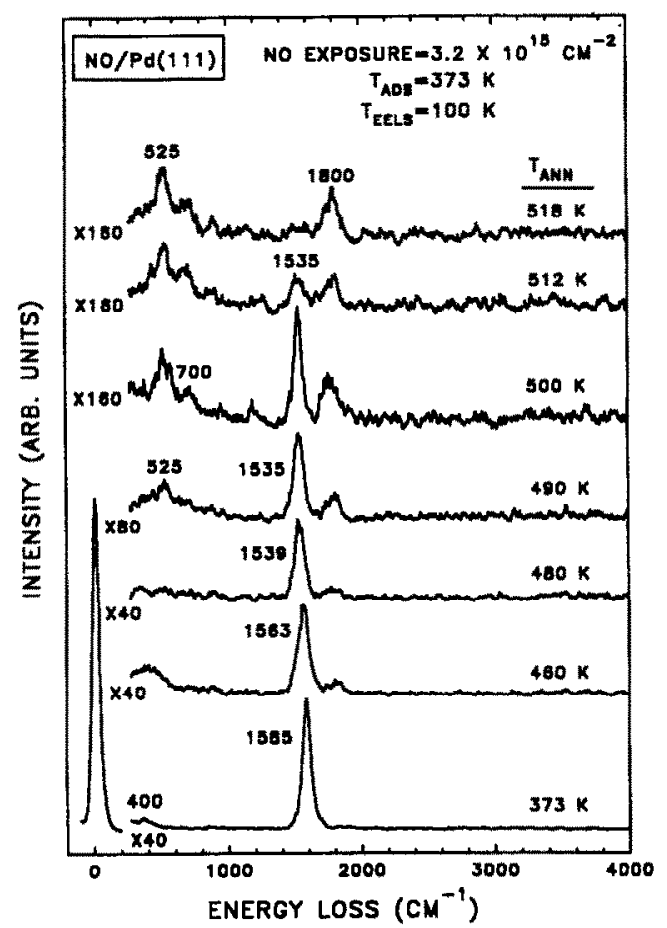

Fig. 12. High resolution electron energy loss spectra for various annealing temperatures following NO adsorption at $373 \mathrm{~K}$ (exposure $=\epsilon=3.2 \times 10^{15} \mathrm{~cm}^{-2}$ ) on $\mathrm{Pd}(111)$. Heating above $490 \mathrm{~K}$ produces $\nu(\mathrm{Pd}-\mathrm{O})$ modes at 525 and $700 \mathrm{~cm}^{-1}$, indicating that NO thermal decomposition has deposited some atomic oxygen on the Pd(111) surface.

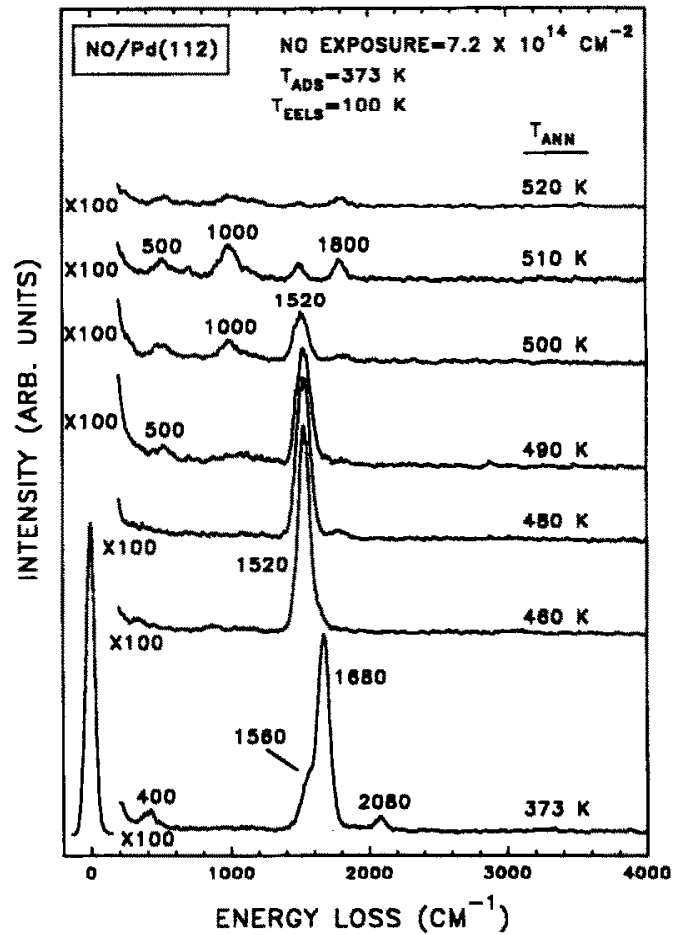

Fig. 13. High resolution electron energy loss spectra for various annealing temperatures following adsorption at $373 \mathrm{~K}$ of a high coverage $\left(\epsilon=7.2 \times 10^{14} \mathrm{~cm}^{-2}\right)$ of NO on Pd(112). Heating to $460 \mathrm{~K}$ desorbs the step-site NO, producing a spectrum (second from the bottom) exhibiting a $\nu(\mathrm{N}-\mathrm{O})$ mode at $1520 \mathrm{~cm}^{-1}$, indicative of the presence of only terrace-bound NO. Heating above $490 \mathrm{~K}$ produces $\nu\left(\mathrm{Pd}-\mathrm{O}\right.$ ) modes at $500 \mathrm{~cm}^{-1}$ (surface $\mathrm{O}$ ) and $1000 \mathrm{~cm}^{-1}$ (sub-surface $\mathrm{O}$ ), indicating that NO thermal decomposition has deposited atomic oxygen at the $\operatorname{Pd}(112)$ surface.

ance of the $\nu(\mathrm{Pd}-\mathrm{O})$ modes in the HREEL spectra (not shown). It should be noted that a weak $\nu(\mathrm{Pd}-$ NO) mode near $400 \mathrm{~cm}^{-1}$ in Fig. 12 (bottom spectrum) falls below HREELS detection limits after annealing to $480 \mathrm{~K}$, and that this mode should not be confused with the $525 \mathrm{~cm}^{-1} \nu(\mathrm{Pd}-\mathrm{O})$ mode observed after heating to $490 \mathrm{~K}$.

Fig. 13 shows the effect of heating on the vibrational spectra of a high coverage of $\mathrm{NO}$ adsorbed on $\mathrm{Pd}(112)$ at $373 \mathrm{~K}$. The disappearance of the 1680 $\mathrm{cm}^{-1} \nu(\mathrm{N}-\mathrm{O})$ mode upon heating to $460 \mathrm{~K}$ (see the bottom two spectra of Fig. 13) is due to the thermal desorption of step-site NO, leaving only terracebound NO on the $\mathrm{Pd}(112)$ surface in the molecular form (see Fig. 11). As the surface is heated above 
$490 \mathrm{~K}$, a $\nu(\mathrm{Pd}-\mathrm{O})$ mode at $500 \mathrm{~cm}^{-1}$ is observed, indicative of NO dissociation. An additional oxygen-related vibrational feature is seen in Fig. 13 near $1000 \mathrm{~cm}^{-1}$, also indicating that $\mathrm{NO}$ decomposes on $\mathrm{Pd}(112)$ upon heating. This $1000 \mathrm{~cm}^{-1}$ mode is believed to result from sub-surface $O$ vibrational modes and will be discussed below.

Both surface-bound $O$ and sub-surface $O$ vibrational features from Pd(112) disappear in HREELS upon heating above $550 \mathrm{~K}$ (not shown), indicating that these species dissolve into the Pd bulk. It is noted that a weak $\nu(\mathrm{Pd}-\mathrm{NO})$ mode observed near $400 \mathrm{~cm}^{-1}$ in Fig. 13 (bottom spectrum) falls below HREELS detection limits upon heating to $480 \mathrm{~K}$, and that this mode should not be confused with the 500 $\mathrm{cm}^{-1} \nu(\mathrm{Pd}-\mathrm{O})$ band observed upon heating to 490 $\mathrm{K}$. In addition, impurity $\mathrm{CO}$ in the presence of high coverage NO produces a weak vibrational loss at $2080 \mathrm{~cm}^{-1}$ in the bottom spectrum of Fig. 13, in addition to the usual $\sim 1800 \mathrm{~cm}^{-1}$ mode seen in some of the other spectra.

The HREELS data of Fig. 14 are presented to show the effect of heating an $\mathrm{NO} / \mathrm{Pd}(112)$ surface following a low NO exposure at $373 \mathrm{~K}$. Here, only terrace sites are initially occupied by NO giving the singular $1525 \mathrm{~cm}^{-1}$ feature. It should be noted that the same features observed previously above $460 \mathrm{~K}$ in Fig. 13 are also evident in Fig. 14. Annealing above $490 \mathrm{~K}$ in Fig. 14 induces a slight decrease in frequency of the $\sim 1525 \mathrm{~cm}^{-1} \nu(\mathrm{N}-\mathrm{O})$ mode and the appearance of bands associated with surfacebound $O\left(520 \mathrm{~cm}^{-1}\right)$ and sub-surface $O\left(990 \mathrm{~cm}^{-1}\right)$. Annealing above $550 \mathrm{~K}$ results in the diffusion of these oxygen species into the Pd bulk.

Comparison of the relative intensities between the $\nu(\mathrm{N}-\mathrm{O})$ mode and the O-related modes in Fig. 13 (high NO coverage) with those of Fig. 14 (low NO coverage) for spectra acquired following 490-510 K annealing indicates that a larger relative amount of $\mathrm{O}$ is present in Fig. 14 than in Fig. 13. This is consistent with the TPD results of Fig. 7, where it was observed that the largest fractional NO decomposition on Pd(112) occurred for the lowest initial NO coverages upon heating.

\subsection{4. $\mathrm{O}_{2} / \mathrm{Pd}(112)$}

Fig. 15 is presented as evidence that the 500 and $1000 \mathrm{~cm}^{-1}$ modes observed by HREELS from

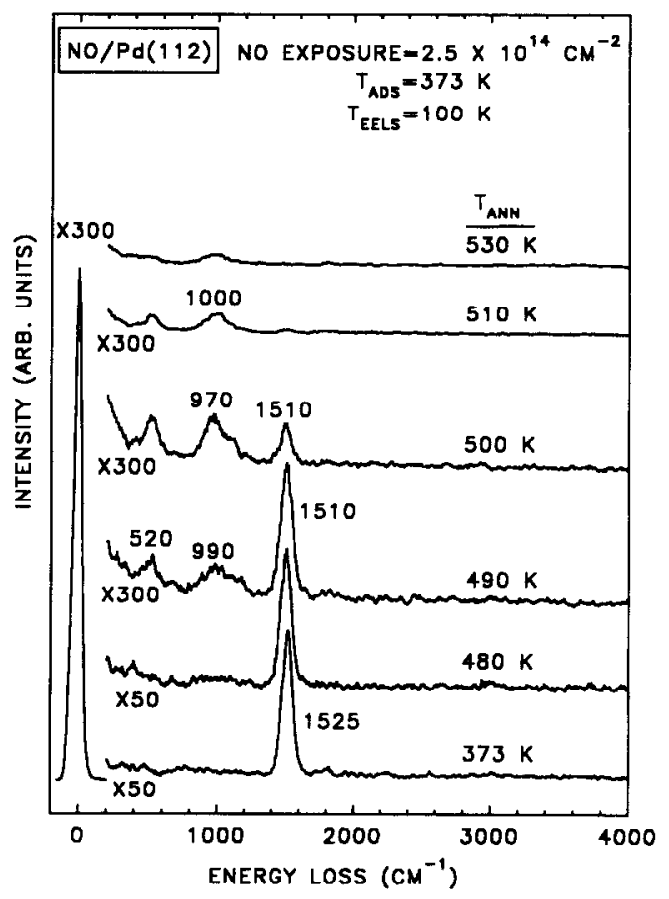

Fig. 14. High resolution electron energy loss spectra for various annealing temperatures following adsorption at $373 \mathrm{~K}$ of a low coverage $\left(\epsilon=2.5 \times 10^{14} \mathrm{~cm}^{-2}\right)$ of NO on $\mathrm{Pd}(112)$. The bottom spectrum, exhibiting a $\nu(\mathrm{N}-\mathrm{O})$ mode at $1525 \mathrm{~cm}^{-1}$, indicates the presence of only terrace-bound NO. Heating above $490 \mathrm{~K}$ produces $\nu\left(\mathrm{Pd}-\mathrm{O}\right.$ ) modes at $520 \mathrm{~cm}^{-1}$ (surface $\mathrm{O}$ ) and $990 \mathrm{~cm}^{-1}$ (sub-surface $\mathrm{O}$ ), indicating that NO thermal decomposition has deposited atomic oxygen at the $\operatorname{Pd}(112)$ surfacc.

Pd(112) following the thermal dissociation of NO are due to O-related vibrations. The left-hand side of Fig. 15 shows the thermal behavior of the vibrational spectra following $373 \mathrm{~K}$ adsorption of a low coverage of $\mathrm{NO}$ on $\mathrm{Pd}(112)$, whereas the right-hand side of Fig. 15 shows spectra acquired under similar conditions resulting from $373 \mathrm{~K}$ exposure of $\mathrm{Pd}(112)$ to $1.8 \times 10^{14} \mathrm{O}_{2} / \mathrm{cm}^{-2}$. Annealing $\mathrm{NO} / \mathrm{Pd}(112)$ to $510 \mathrm{~K}$ produces vibrational modes at 520 and 1000 $\mathrm{cm}^{-1}$, whereas annealing $\mathrm{O}_{2} / \mathrm{Pd}(112)$ to $500 \mathrm{~K}$ produces a vibrational spectrum with 485 and 990 $\mathrm{cm}^{-1}$ vibrational features, as seen by comparing the bottom two spectra of Fig. 15. Also evident in Fig. 15 is the fact that annealing either system to above $550 \mathrm{~K}$ results in the decrease in intensity of these vibrational features to below HREELS detection limits. It should be noted that all of the spectra of Fig. 15 are plotted on the same scale. 


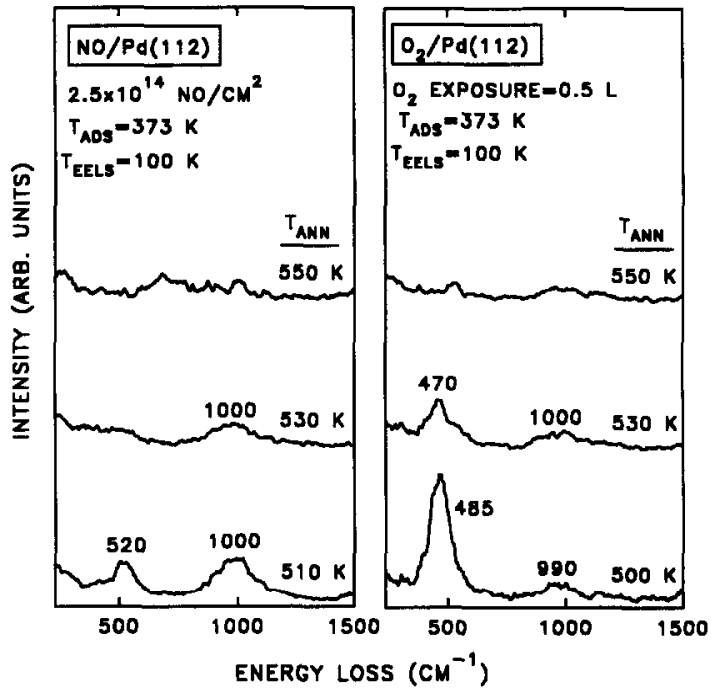

Fig. 15. High resolution electron energy loss spectra for various annealing temperatures following adsorption at $373 \mathrm{~K}$ of low coverages of NO ( $\epsilon=2.5 \times 10^{14} \mathrm{~cm}^{-2}$, left-hand side) and $\mathrm{O}_{2}$ $\left(\epsilon=0.5\right.$ langmuir $=1.8 \times 10^{14} \mathrm{~cm}^{-2}$, right-hand side) on $\operatorname{Pd}(112)$. The vibrational modes of surface $O\left(\sim 500 \mathrm{~cm}^{-1}\right)$ and sub-surface $\mathrm{O}\left(\sim 1000 \mathrm{~cm}^{-1}\right)$ on $\mathrm{Pd}(112)$ are seen to exhibit similar thermal behavior in both systems. The disappearance of these bands above $550 \mathrm{~K}$ indicates the dissolution of $\mathrm{O}$ into the Pd bulk. The spectra are all plotted on the same scale.

These HREELS results, showing two vibrational bands which exhibit similar frequencies and thermal behavior on $\mathrm{Pd}(112)$ exposed to either $\mathrm{NO}$ or $\mathrm{O}_{2}$ under similar conditions, indicate that these $\sim 500$ and $\sim 1000 \mathrm{~cm}^{-1}$ modes are due to $\mathrm{Pd}-\mathrm{O}$ vibrations. It is noteworthy that only $\sim 500 \mathrm{~cm}^{-1}$, and no $\sim 1000 \mathrm{~cm}^{-1}$ vibrational features were observed by HREELS following $\mathrm{NO}$ or $\mathrm{O}_{2}$ thermal dissociation on $\mathrm{Pd}(111)$ under conditions similar to those present in Fig. 15. Thus it appears that the formation of sub-surface $O\left(1000 \mathrm{~cm}^{-1}\right.$ band $)$ is favored on Pd(112) as compared to Pd(111).

The HREELS data of Fig. 16 serve to illustrate one important point; pre-adsorbed oxygen does not preferentially block either the terrace sites or the step sites on Pd(112) toward NO adsorption. It is clear in Fig. 16 that NO adsorption at $373 \mathrm{~K}$ on clean (left-hand side) or O-covered (right-hand side) $\mathrm{Pd}(112)$ results in similar $\nu(\mathrm{N}-\mathrm{O})$ vibrational bands for roughly the same NO exposures.

\subsection{Electron stimulated desorption ion angular distributions}

All of the ESDIAD data presented here were measured in the same UHV chamber at $100 \mathrm{~K}$ following adsorption of ${ }^{14} \mathrm{NO}$ at $300 \mathrm{~K}$ on clean $\operatorname{Pd}(111)$ and $\mathrm{Pd}(112)$ surfaces. $\mathrm{O}^{+}$ions were the only detectable particles observed during ESD from adsorbed NO in this study, and details about the $\mathrm{O}^{+}$ ion identification, the $\mathrm{O}^{+}$ion kinetic energy distributions, and the dependence of the $\mathrm{O}^{+}$ion yield on the incident electron energy are presented in the Appendix. The $\mathrm{O}^{+}$ESDIAD patterns are shown in both perspective views and contour plots, the latter being generated by eight equal separations extending from $25 \%$ to $95 \%$ of the maximum counts on each plot. The ESDIAD patterns are shown with angular coordinate axes (which are slightly non-linear), arranged so that the macroscopic surface normal $(\langle 111\rangle$ for

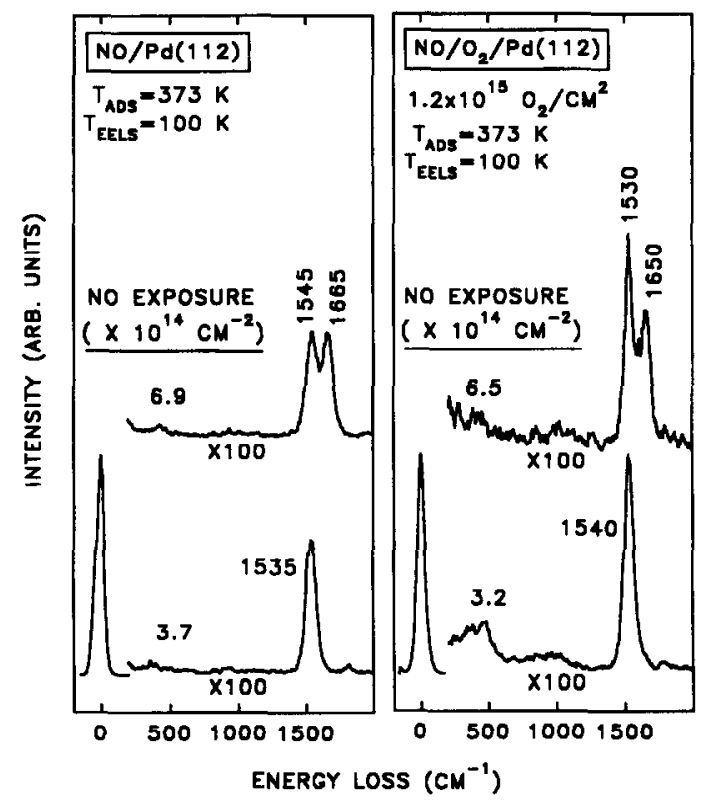

Fig. 16. High resolution electron energy loss spectra following $373 \mathrm{~K}$ adsorption of $\mathrm{NO}$ on clean (left-hand side) and $\mathrm{O}$ precovered (right-hand side) $\operatorname{Pd}(112)$. It is evident that essentially the same $\nu(\mathrm{N}-\mathrm{O})$ modes are observed in both systems following nearly identical NO exposures. This result indicates that pre-adsorbed $O$ does not preferentially block either the terrace sites or the step sites of $\mathrm{Pd}(112)$ toward NO adsorption under these conditions. 
$\operatorname{Pd}(111)$ and $\langle 112\rangle$ for $\mathrm{Pd}(112))$ would project through the $\left(0^{\circ}, 0^{\circ}\right)$ point of the patterns. The maximum polar angle of acceptance for positive ions (with respect to the surface normal) of the ESDIAD detector is roughly $48^{\circ}$.

\subsection{1. $N O / P d(111)$}

Figs. 17 and 18 present $\mathrm{O}^{+}$ESDIAD patterns recorded with an incident electron energy of $800 \mathrm{eV}$ from NO/Pd(111). The NO exposures employed in Figs. 17 and 18 were (a) 3.3 , (b) 5.5, (c) 6.7, and (d) $8.9 \times 10^{14} \mathrm{~cm}^{-2}$. As can be seen in Figs. 17 and 18, the ESDIAD patterns from NO/Pd(111) consist of a single $\mathrm{O}^{+}$beam, oriented along the $\langle 111\rangle$ surface normal direction. In addition, since all of the ESDIAD patterns of Fig. 17 are plotted on the same scale, it is evident that the $\mathrm{O}^{+}$signal increases with NO exposure. This is also seen in the contour plots of Fig. 18, where at low NO coverage (Fig. 18a) the noise level is at or above $25 \%$ of the maximum counts in that pattern, whereas at high NO coverage (Fig. 18(d)) this is not the case.

The integrated $\mathrm{O}^{+}$ESDIAD signal calculated from data like those of Figs. 17 and 18 is shown in Fig. 19 versus NO exposure. It is evident from Fig. 19 that the $\mathrm{O}^{+}$yield from $\mathrm{NO} / \mathrm{Pd}(111)$ rises monotonically as the NO exposure is increased, tending toward saturation at high NO exposures. The error bars of Fig. $19( \pm 5 \%)$ arise mainly from uncertainties due to the subtraction of a large X-ray background $[6,7]$ followed by normalization.

Fig. 20 presents the half width at half-maximum (HWHM) of the same $\mathrm{O}^{+}$ESDIAD patterns from $\mathrm{NO} / \mathrm{Pd}(111)$ analyzed for total $\mathrm{O}^{+}$yield in Fig. 19. It can be seen that within detection limits, the $\mathrm{O}^{+}$ ESDIAD patterns remain centered about the $\langle 111\rangle$ crystal azimuth and maintain a HWHM of $\sim 6^{\circ}$ throughout the NO exposure range tested. This indi-

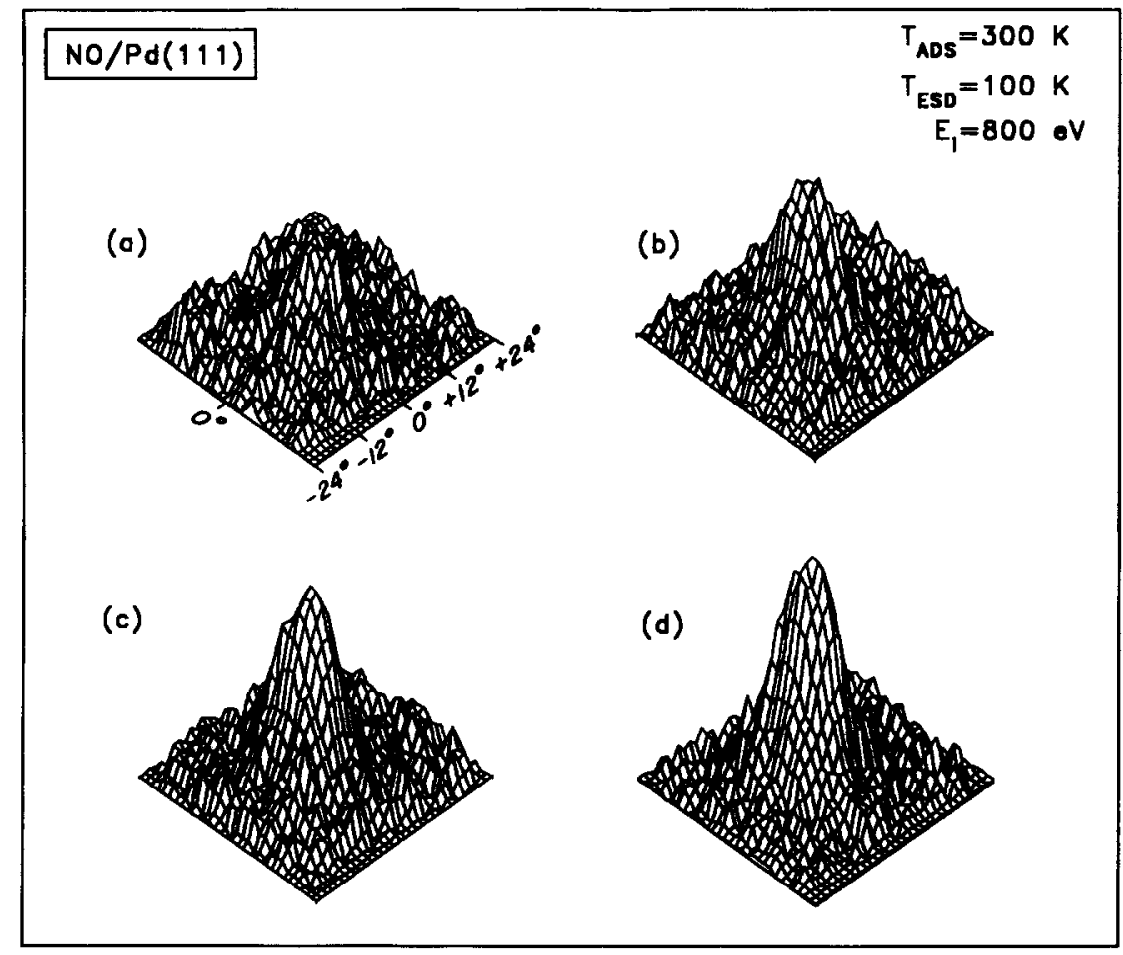

Fig. 17. Electron stimulated desorption ion angular distribution patterns (perspective views) of $\mathrm{O}^{+}$ions desorbed from NO/Pd(111) following various NO exposures at $300 \mathrm{~K}$. The $\mathrm{O}^{+}$pattern is centered about the $\langle 111\rangle$ surface normal direction $\left(0^{\circ}, 0^{\circ}\right)$ at all coverages, indicating that the $\mathrm{N}-\mathrm{O}$ bond remains normally oriented on $\mathrm{Pd}(111)$ under these conditions. The incident electron energy employed was 800 $\mathrm{eV}$ and the NO exposures, in units of $10^{14} \mathrm{~cm}^{-2}$, were (a) 3.3 , (b) 5.5 , (c) 6.7 , and (d) 8.9 . The patterns are all plotted on the same scale, and the slightly non-linear axes (in deg) are provided for reference. 
cates that under these conditions the NO molecules remain upright on $\operatorname{Pd}(111)$, with no evidence for tilted NO species being detected throughout the NO coverage range studied here. The error bars of Fig. 20 represent the absolute mean deviation in calculating the HWHM from the ESDIAD data.

\subsection{2. $N O / P d(112)$}

The ESDIAD patterns of Figs. 21 and 22 were acquired with an incident electron energy of $1000 \mathrm{eV}$ from NO/ $\mathrm{Pd}(112)$. The crystal was positioned so that the step edge direction $(\langle\overline{1} 10\rangle$ azimuth) is parallel to the left-hand border of each ESDIAD pattern (verified by LEED). In these figures, the $\langle 112\rangle$ macroscopic crystal normal would intersect the $\left(0^{\circ}, 0^{\circ}\right)$ coordinate, whereas the $\langle 111\rangle$ terrace normal direction lies near $\left(+19.5^{\circ}, 0^{\circ}\right)$. Angles less than $0^{\circ}$ in the direction perpendicular to the step edges correspond to the 'downstairs' direction, which is characteristic of NO adsorption on the step sites of $\operatorname{Pd}(112)$.

As can be seen in Figs. 21a and Fig. 22a, a low NO exposure $\left(1.0 \times 10^{14} \mathrm{~cm}^{-2}\right)$ on $\mathrm{Pd}(112)$ produces a single $\mathrm{O}^{+}$ESDLAD beam which is ejected near to the $\langle 111\rangle$ terrace normal direction, indicative of $N O$ adsorption initially on terrace sites. This single $\mathrm{O}^{+}$beam is observed up to NO exposures of $5.0 \times 10^{14} \mathrm{~cm}^{-2}$, as shown in Figs. $21 \mathrm{~b}$ and $22 \mathrm{~b}$. However, at an exposure of $6.0 \times 10^{14} \mathrm{~cm}^{-2}$ (Figs. 21c and 22c), NO/Pd(112) produces an ESDIAD pattern consisting of two $\mathrm{O}^{+}$beams, one oriented near the $\langle 111\rangle$ terrace normal and the second in the 'downstairs' direction. This second $\mathrm{O}^{+}$beam increases in intensity at higher NO exposures $(2.0 \times$ $10^{15} \mathrm{~cm}^{-2}$, Figs. $21 \mathrm{~d}$ and $22 \mathrm{~d}$ ), indicating the increased occupation of $\operatorname{Pd}(112)$ step sites by NO

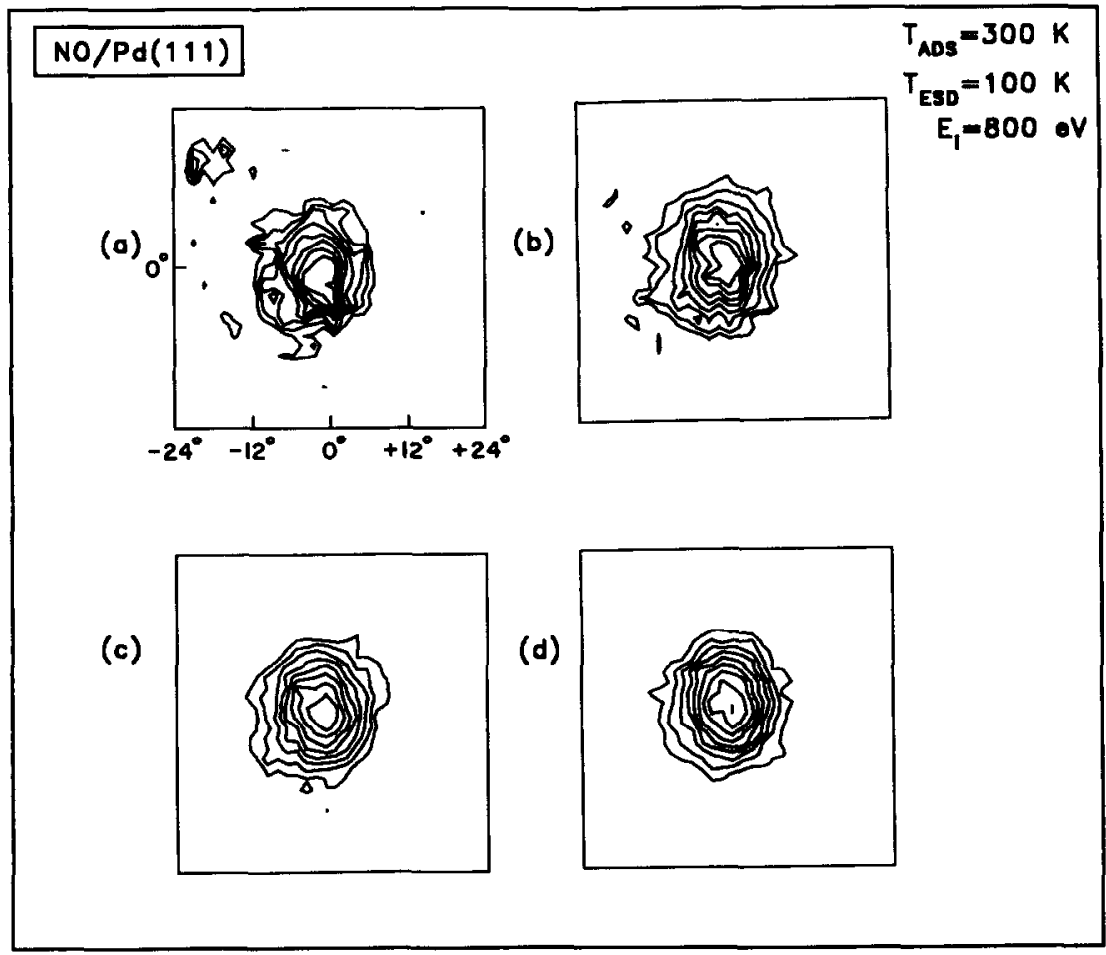

Fig. 18. Electron stimulated desorption ion angular distribution patterns (contour plots) of $\mathrm{O}^{+}$ions desorbed from NO/Pd(111) following various NO exposures at $300 \mathrm{~K}$. The $\mathrm{O}^{+}$pattern is centered about the $\langle 111\rangle$ surface normal direction $\left(0^{\circ}, 0^{\circ}\right)$ at all coverages, indicating that the $\mathrm{N}-\mathrm{O}$ bond remains normally oriented on $\mathrm{Pd}(111)$ under these conditions. The incident electron energy employed was $800 \mathrm{eV}$ and the NO exposures, in units of $10^{14} \mathrm{~cm}^{-2}$, were (a) 3.3 , (b) 5.5 , (c) 6.7 , and (d) 8.9 . The contour plots are generated by eight equal separations extending from $25 \%$ to $95 \%$ of the maximum counts in each plot, and the slightly non-linear axes (in deg) are provided for reference. 


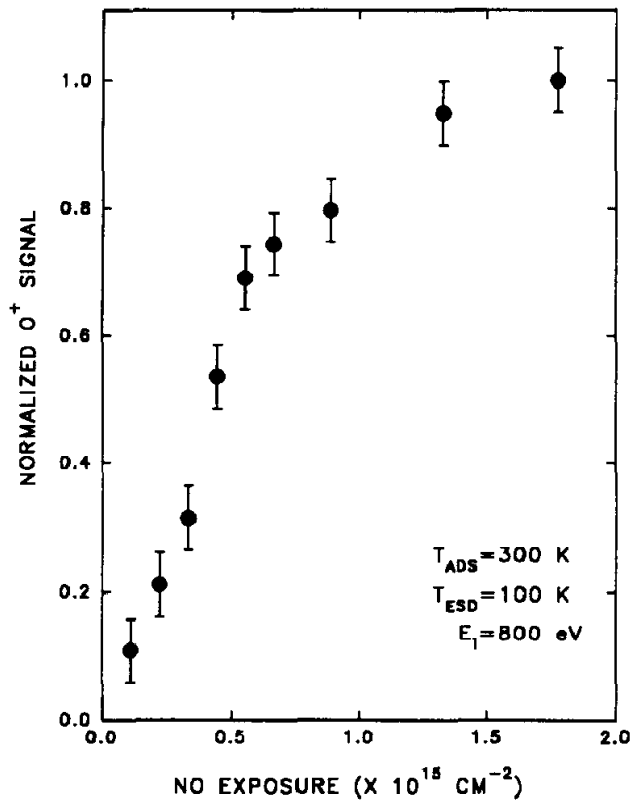

Fig. 19. Normalized yield of $\mathrm{O}^{+}$ions desorbed from $\mathrm{NO} / \mathrm{Pd}(111)$ by electron stimulated desorption following adsorption at $300 \mathrm{~K}$ of various amounts of NO. The monotonic rise and saturation of the $\mathrm{O}^{+}$signal indicates the filling of the $\mathrm{Pd}(111)$ surface at $300 \mathrm{~K}$ by NO. The incident electron beam energy employed was $800 \mathrm{eV}$.

during later stages of adsorption. The ESDIAD results of Figs. 21 and 22 are entirely consistent with the HREELS data of Fig. 11, as will be discussed in detail below.

\section{Discussion}

The adsorption of NO on various single crystal Pd surfaces has been studied by a variety of techniques $[11,14,16-29]$. This study provides insight into the behavior of $\mathrm{NO} / \mathrm{Pd}$ systems by detailed comparisons of data obtained from $\mathrm{Pd}(111)$ and $\mathrm{Pd}(112)$ surfaces under well-controlled conditions in the same laboratory. The properties of NO adsorbed on $\mathrm{Pd}(112)$ (composed of 3-atom-wide (111) terraces and monatomic (001) steps) has not been studied previously (to our knowledge) except in this laboratory $[14,16]$. In addition, this is believed to be the first detailed report of the ESD behavior of NO adsorbed on well-characterized Pd single crystal surfaces.

\subsection{Thermal desorption and thermal decomposition of $N O$}

The only thermal desorption species observed in this study from $\mathrm{NO} / \mathrm{Pd}(111)$ and $\mathrm{NO} / \mathrm{Pd}(112)$ were $\mathrm{NO}, \mathrm{N}_{2}$, and $\mathrm{N}_{2} \mathrm{O}$. The observation of only these three thermal desorplion species, and not $\mathrm{O}_{2}$ or $\mathrm{NO}_{2}$, seems to be a consistent characteristic in a variety of NO/Pd systems $[11,17,18,26,28]$. These results imply that during heating, $\mathrm{NO}$ adsorbed on these $\mathrm{Pd}$ surfaces undergoes disproportionation reactions which favor the thermal desorption of $\mathrm{N}$-containing species and preferentially deposit $\mathrm{O}$ at the Pd surfaces. This general conclusion, based on TPD results, will also be substantiated below by HREELS for the two specific cases considered in this study.

\subsection{1. $N O / P d(111)$}

The TPD results of this study indicate that only minimal thermal decomposition of NO accurs on

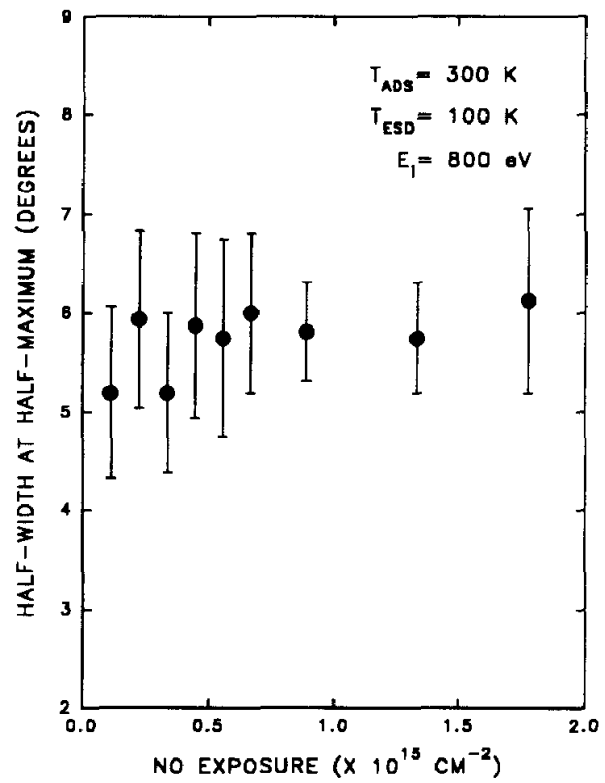

Fig. 20. Half width at half maximum (HWHM) of the $\mathrm{O}^{+}$ion angular distributions from $\mathrm{NO} / \mathrm{Pd}(111)$ produced by electron stimulated desorption following $300 \mathrm{~K}$ adsorption of various amounts of NO. Within measurement limits, the IIWHM maintains a value of $\sim 6^{\circ}$, independent of the NO coverage. This result indicates that no evidence for tilted $\mathrm{NO}$ on $\mathrm{Pd}(111)$ is observed under these coverage conditions. The incident electron beam energy employed was $800 \mathrm{eV}$, and the data were acquired under field-free conditions. 
Pd(111) during heating. This conclusion is based on the small relative yields of NO dissociation products, $\mathrm{N}_{2}$ and $\mathrm{N}_{2} \mathrm{O}$, observed during TPD, and is consistent with previous conclusions about the thermal behavior of $\mathrm{NO} / \mathrm{Pd}(111)[14,17,21,23,24]$. It is likely that the low yield of NO decomposition products originates from defect sites on the Pd(111) single crystal used in this work. With this knowledge, it is reasonable to neglect the minority reaction channel (NO thermal decomposition) and to analyze the TPD spectra from NO/Pd(111) (Fig. 1) in detail in order to extract the kinetic parameters of NO thermal desorption.

The results of the application of TTPD analysis [15] to the TPD spectra of Fig. 1 appear in Figs. 2 and 3 . The most obvious feature seen by comparison of Figs. 2 and 3 is that both kinetic parameters vary with NO exposure in the same manner. This 'compensation effect' has been observed in many adsorbate/substrate systems where lateral interactions between adsorbed particles play an important role [3033]. Thus the decrease in $E_{\text {act }}$ with increased NO exposure in Fig. 2 is interpreted as resulting from repulsive NO-NO interactions, which increase in strength as the average NO-NO distance decreases.

The second striking feature of Figs. 2 and 3 is that in the limit of zero coverage, the values of $E_{\mathrm{act}}=$ $E_{\text {act }}^{0} \approx 180 \mathrm{~kJ} / \mathrm{mol}$ and the pre-exponential factor $\sim 10^{17} \mathrm{~s}^{-1}$ differ significantly from those usually found from a Redhead first-order desorption kinetic analysis [34]. However, the Redhead analysis assumes that no interactional effects occur between

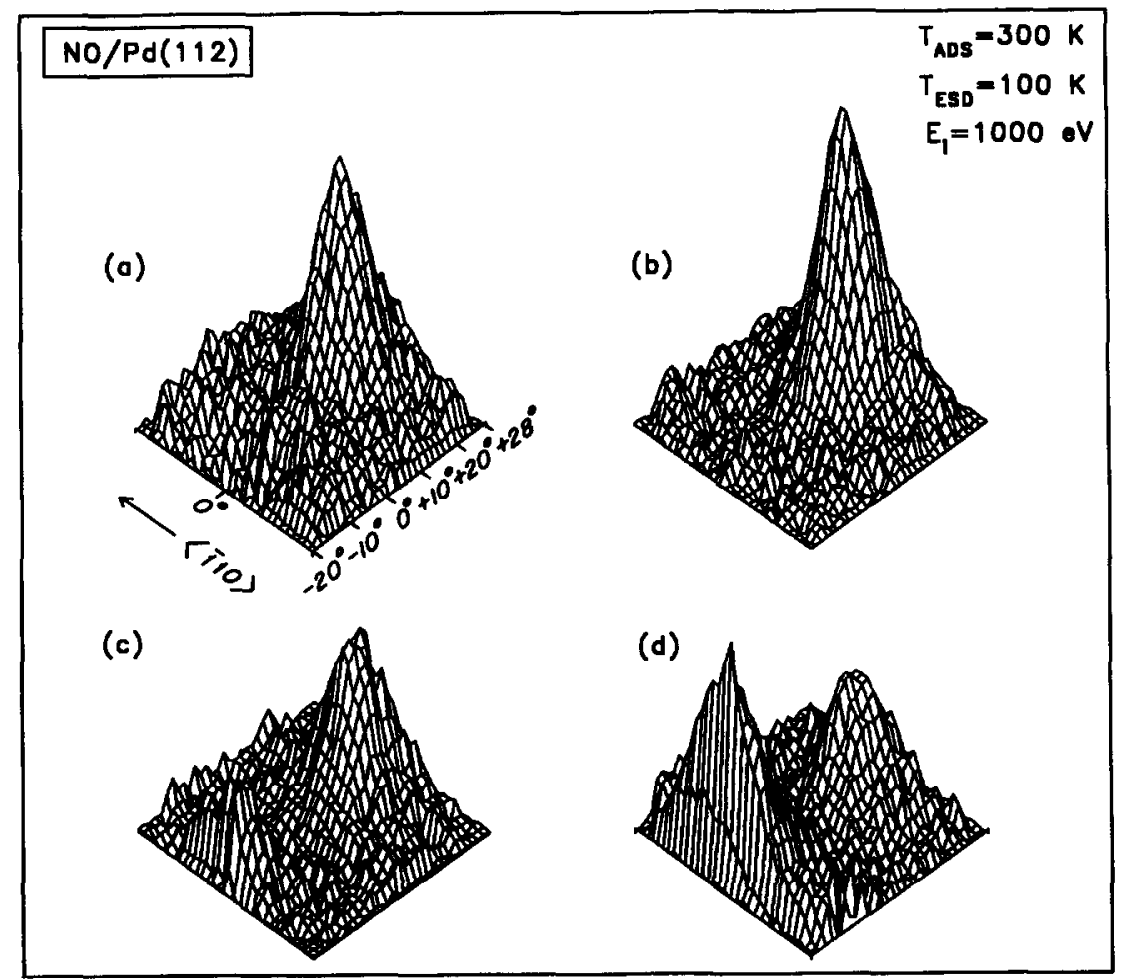

Fig. 21. Electron stimulated desorption ion angular distribution patterns (perspective views) of $\mathrm{O}^{+}$ions desorbed from NO/Pd(112) following various $300 \mathrm{~K}$ NO exposures. All of the patterns contain an $\mathrm{O}^{+}$beam near the $\langle 111\rangle$ terrace normal direction $\left(+19.5^{\circ}, 0^{\circ}\right)$, resulting from NO adsorbed on the (111) terraces of $\mathrm{Pd}(112)$. A second $\mathrm{O}^{+}$beam, in the 'downstairs' direction $\left(-16^{\circ}, 0^{\circ}\right)$ is observed only at higher NO coverages, and results from NO adsorbed on the (001) steps of $\mathrm{Pd}(112)$. The incident electron energy employed was $1000 \mathrm{eV}$ and the NO exposures, in units of $10^{14} \mathrm{~cm}^{-2}$, were (a) 1.0, (b) 5.0, (c) 6.0, and (d) 20. The patterns are all plotted on the same scale, and the slightly non-linear axes (in $\mathrm{deg}$ ) are provided for reference. The macroscopic surface normal direction $(\langle 112\rangle)$ would intersect the patterns at $\left(0^{\circ}, 0^{\circ}\right)$, and the step edges $(\langle 110\rangle)$ run parallel to the left-hand border of each plot. 
adsorbates (i.e., $E_{\text {act }}=$ constant, independent of coverage).

It should be noted that no ordered LEED patterns from $\mathrm{NO}$ adsorbed on $\mathrm{Pd}(111)$ at $300 \mathrm{~K}$ were observed in this study, which is consistent with previous reports $[17,22]$. Thus the absolute NO surface coverage on $\operatorname{Pd}(111)$ following saturation of the $\sim 510 \mathrm{~K} \mathrm{NO}$ desorption state is difficult to determine, and estimates range from $1 / 4 \mathrm{ML}$ [17] to $3 / 8$ ML [22] to 0.43 ML [24].

The only detailed data available on coverage-dependent measurements of $E_{\text {act }}$, for NO desorption from a $\mathrm{Pd}$ surface with a structure similar to those studied here, were presented by Schmick and Wassmuth [18]. Those authors studied NO adsorption on a stepped $\mathrm{Pd}(111)$ crystal, cut at a $3^{\circ}$ angle with re- spect to the (111) face and exhibiting average (111) terrace widths of 16 atomic rows [18]. TPD spectra $(\mathrm{d} T / \mathrm{d} t=10.0 \mathrm{~K} / \mathrm{s})$ indicated the thermal desorption of $\mathrm{NO}$ and $\mathrm{N}_{2} \mathrm{O}$ near $500 \mathrm{~K}$, and two $\mathrm{N}_{2}$ desorption maxima near 500 and $625 \mathrm{~K}$ [18]. The yield from the high temperature $\mathrm{N}_{2}$ desorption state became saturated at low NO exposures, and no mention of the use of isotopic NO to verify these results was made [18]. Pre-exposure of the stepped surface to 0.4 langmuir of $\mathrm{O}_{2}$ was found to completely eliminate the thermal dissociation of NO on this surface, presumably by blocking of the step sites by $O(a)[18]$.

The TPD spectra $\left(T_{\text {ads }}=350 \mathrm{~K}\right)$ presented by Schmick and Wassmuth of NO from the stepped Pd surface, which was passivated toward NO dissocia-

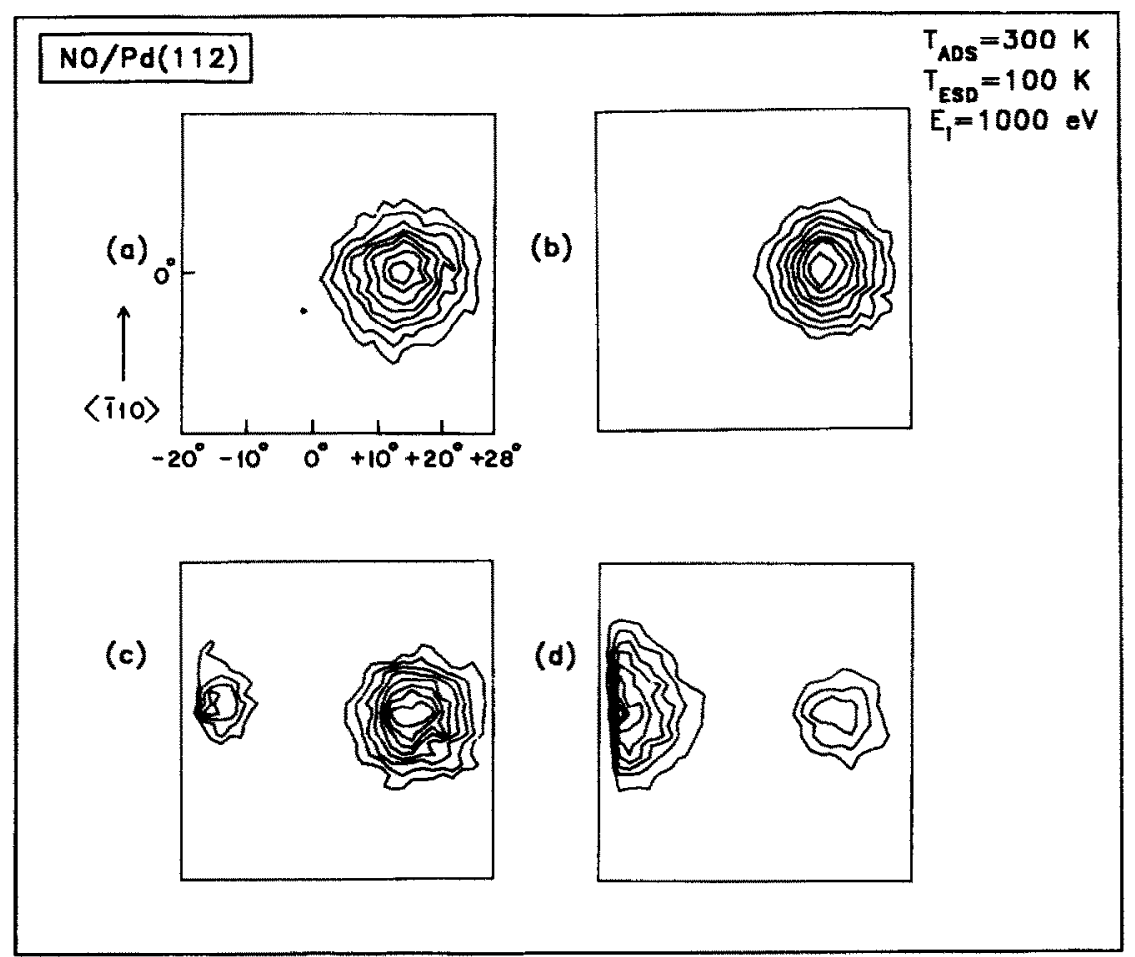

Fig. 22. Electron stimulated desorption ion angular distribution patterns (contour plots) of $\mathrm{O}^{+}$ions desorbed from $\mathrm{NO} / \mathrm{Pd}(112)$ following various NO exposures at $300 \mathrm{~K}$. All of the patterns contain an $\mathrm{O}^{+}$beam near the $\langle 111\rangle$ terrace normal direction $\left(+19.5^{\circ}, 0^{\circ}\right)$, resulting from NO adsorbed on the (111) terraces of Pd(112). A second $\mathrm{O}^{-}$beam, in the 'downstairs' direction $\left(-16^{\circ}, 0^{\circ}\right)$ is observed only at higher NO coverages, and results from NO adsorbed on the (001) steps of Pd(112). The incident electron energy employed was $1000 \mathrm{eV}$ and the NO exposures, in units of $10^{14} \mathrm{~cm}^{-2}$, were (a) 1.0, (b) 5.0 , (c) 6.0 , and (d) 20 . The contour plots are generated by eight equal separations extending from $25 \%$ to $95 \%$ of the maximum counts in each plot, and the slightly non-linear axes (in deg) are provided for reference. The macroscopic surface normal direction $(\langle 112\rangle)$ would intersect the patterns at $\left(0^{\circ}, 0^{\circ}\right)$, and the step edges $(\langle 110\rangle)$ run parallel to the left-hand border of each plot. 
tion by pre-exposure to 0.75 langmuir of $\mathrm{O}_{2}$ [18], exhibit the same general characteristics as those shown in Fig. 1. In addition, the data shown by Schmick and Wassmuth [18] for $E_{\text {act }}$ versus NO coverage calculated via isothermic and isosteric desorption rates is also very similar in appearance to the data presented in Fig. 2. The only significant difference between the data of Fig. 2 and the qualitatively similar data of Schmick and Wassmuth [18] is the absolute magnitude of the energy scale for $E_{\text {act }}$. In Fig. 2, $E_{\text {act }}$ for $\mathrm{NO} / \mathrm{Pd}(111)$ varies from $\sim 180$ to $\sim 90 \mathrm{~kJ} / \mathrm{mol}$, whereas Schmick and Wassmuth observed that $E_{\text {act }}$ ranges from $\sim 147$ to $\sim 71$ $\mathrm{kJ} / \mathrm{mol}$ for $\mathrm{NO}$ from the O-passivated (stepped) Pd(111) crystal [18].

The most reasonable explanation for these observed differences is that the presence of $O$ on the surface studied by Schmick and Wassmuth [18] acts to lower the binding energy of NO at all coverages. Due to the 'compensation effect' [30-33], the absolute magnitude of the pre-exponential factor $(v)$ for NO desorption presented here is also larger than reported by Schmick and Wassmuth [18], who indicate a value of $2.6 \times 10^{14} \mathrm{~s}^{-1}$ at low NO coverage. A comparison of Figs. 2 and 3 indicates that in our experiments, when $E_{\text {act }}$ has decreased to $147 \mathrm{~kJ} / \mathrm{mol}$ at a finite NO coverage, our value for the pre-exponential factor is also $\sim 10^{14} \mathrm{~s}^{-1}$. This could indicate that neighboring $\mathrm{NO}$ molecules act like $\mathrm{O}$ neighbors in reducing $E_{\text {act }}$ and $v$, or that our kinetic measurements giving higher $E_{\text {act }}$ and $v$ at low coverage are carried out at lower coverages than those of Ref. [18].

The most important conclusions based on the TPD data of this section are that minimal thermal decomposition of NO occurs on Pd(111). In addition, strong repulsive interactions between the adsorbed NO molecules significantly lower the observed kinetic parameters for NO thermal desorption from $\mathrm{Pd}(111)$ as the NO surface coverage is increased.

\subsection{2. $N O / P d(112)$}

The thermal desorption results from $\mathrm{NO} / \mathrm{Pd}(112)$ shown in Figs. 4-6 indicate that NO undergoes partial dissociation on $\mathrm{Pd}(112)$ upon heating. As can be seen by the eye, and verified by integration [14], the TPD yields of $\mathrm{N}_{2}$ and $\mathrm{N}_{2} \mathrm{O}$ (Figs. 5 and 6 , respectively) from $\mathrm{NO} / \mathrm{Pd}(112)$ do not saturate as the NO exposure rises. This result indicates that the amount of NO which decomposes on $\mathrm{Pd}(112)$ upon heating is not limited by the (fixed) number of defect or step sites on the $\mathrm{Pd}(112)$ surface. Additionally, the relative yields observed in Fig. 7 for the thermal desorption products of $\mathrm{NO}$ dissociation $\left(\mathrm{N}_{2}\right.$ and $\left.\mathrm{N}_{2} \mathrm{O}\right)$ indicate that the greatest fraction of $\mathrm{NO}$ molecules decompose upon heating at the lowest NO exposures. Although the absolute yield of each species increases as the NO exposure rises [14], the relative yields fall to a constant ratio as the NO coverage is increased, as shown in Fig. 7.

These observations based on TPD data indicate that lateral interactions between the species present on the surface during heating play an important role in determining the rate of NO dissociation with respect to the rate of NO desorption. As was observed in Fig. 2, repulsive NO-NO interactions lower the NO binding energy on $\mathrm{Pd}(111)$ by roughly $50 \%$ over the same exposure range in which the relative yields of $\mathrm{N}_{2}$ and $\mathrm{N}_{2} \mathrm{O}$ from $\mathrm{NO} / \mathrm{Pd}(112)$ fall sharply (Fig. 7). In addition, since NO undergoes significantly more thermal decomposition on $\operatorname{Pd}(112)$ than on $\mathrm{Pd}(111)$ upon heating [14], lateral interactions between different adsorbed particles (NO, $\mathrm{O}$ and $\mathrm{N}$ ) should be more important on Pd(112). The complex ity of systems exhibiting lateral interactions between different adsorbates has been considered theoretically [30], but such treatments would need to be modified for application here due to the anisotropy presented by the stepped $\operatorname{Pd}(112)$ surface.

Results very similar to those of Fig. 7 were reported by Davies and Lambert in a study of the thermal behavior of NO adsorbed on a stepped Pd(331) surface [11]. The Pd(331) surface facetted after cleaning in UHV, but the $(1 \times 1) \operatorname{Pd}(331)$ structure could be stabilized by the presence of $\mathrm{O}$ or $\mathrm{S}$ [11]. TPD spectra $(\mathrm{d} T / \mathrm{d} t=20.0 \mathrm{~K} / \mathrm{s})$ recorded after NO adsorption at room temperature on the $(1 \times 1) \mathrm{Pd}(331)$ surface indicated $\mathrm{NO}, \mathrm{N}_{2}$ and $\mathrm{N}_{2} \mathrm{O}$ thermal desorption near $550 \mathrm{~K}$ [11]. The relative yields of $\mathrm{N}_{2}$ and $\mathrm{N}_{2} \mathrm{O}$ presented by Davies and Lambert also decreased rapidly as the NO exposure was increased [11], exhibiting behavior qualitatively similar to the data shown here in Fig. 7.

The major trend observed in the data of Fig. 7 can be qualitatively explained by a model proposed by Davies and Lambert [11]. In this scenario, low cover- 
ages of NO preferentially dissociate to $N(a)$ and $O(a)$ upon heating, due to the availability of many open Pd sites for accomodation of the products. Subsequent binary surface reactions then form $\mathrm{N}_{2}$ and $\mathrm{N}_{2} \mathrm{O}$, which thermally desorb in relatively large quantities. In contrast, at high NO coverages few unoccupied $\mathrm{Pd}$ sites are available to bind the $\mathrm{N}$ and $\mathrm{O}$ products of $\mathrm{NO}$ decomposition. Therefore, NO desorption is favored over NO dissociation at high NO coverages, decreasing the relative yields of $\mathrm{N}_{2}$ and $\mathrm{N}_{2} \mathrm{O}$ that thermally desorb.

The most significant conclusions based on the TPD data of this section are that the presence of the (001) step sties on Pd(112) enhances the dissociation of NO upon heating, with respect to that observed from NO/Pd(111). In addition, the thermal decomposition of $\mathrm{NO}$ on $\mathrm{Pd}(112)$ is most important at low NO coverage, where only the (111) terrace sites are occupied by NO. Thus the criterion for NO thermal dissociation on $\mathrm{Pd}(112)$ is not step-site adsorption, but rather the presence of the empty step sites during heating, where surface diffusion, inter-particle lateral interactions, molecular decomposition and molecular desorption all occur simultaneously.

\subsection{Vibrational properties of chemisorbed NO}

The bonding of NO to metals (M) has historically been well-studied through investigation of metal nitrosyl complexes [35]. From such studies, it is generally concluded that NO bonds to metals through the nitrogen atom, which donates its lone pair electrons to the empty d orbitals of the metal to form a $u$-type $\mathrm{M}-\mathrm{NO}$ bond. In addition, back-donation of electron density from the metal $d$ orbitals into the $\pi^{*}$ molecular orbitals of NO usually occurs. Here the extra $2 \pi$ electron in NO dominates in determining the $\mathrm{M}-\mathrm{NO}$ bond strength [36]. The relative efficiency of these competing exchanges of electron density between NO and the metal will determine the 'effective charge' that remains localized on the NO group after M-NO bond formation. Strong back-donation from the metal increases the $\mathrm{NO}^{-}$character of the $\mathrm{M}-\mathrm{NO}$ complex, and results in a weak $\mathrm{N}-\mathrm{O}$ bond, exhibiting a low $\nu(\mathrm{N}-\mathrm{O})$ stretching frequency, and a strong $\mathrm{M}-\mathrm{NO}$ bond. Since the $\nu(\mathrm{N}-\mathrm{O})$ frequency depends strongly on the 'effective charge' on the NO group, predictions of the bonding geometry of NO based strictly on this vibrational frequency are questionable [35].

Neverthelcss, many vibrational spectroscopic investigations of NO adsorbed on well-characterized metal surfaces have utilized the frequency of the $\nu(\mathrm{N}-\mathrm{O})$ mode to predict the bonding geometry of $\mathrm{NO}$ at the surface (i.e. bridged, terminal, linear, bent, etc.). These assignments may be correct in some cases, but significant doubts have been recently raised as to the validity of assigning the adsorbate bonding geometry from vibrational spectra for the NO/ $\mathrm{Ni}(111)$ [37-39] and NO/Pt(111) [39] systems. Using photoelectron diffraction $(\mathrm{PhD})$ [37], surface-extended X-ray absorption fine structure (SEXAFS) [38], and dynamical LEED [39] methods, quantitative bond lengths and geometries of NO adsorbed on Ni(111) [37-39] and Pt(111) [39] have been determined. These studies indicate that NO maintains a threefold coordinated hollow site bonding configuration on these two surfaces under conditions where the $\nu(\mathrm{N}-\mathrm{O})$ frequency can vary from 1500 to 1800 $\mathrm{cm}^{-1}$. However, these $\nu(\mathrm{N}-\mathrm{O})$ frequencies of NO adsorbed on metal surfaces are usually interpreted by vibrational spectroscopists as indicating NO bound in twofold bridged and terminal sites, respectively [26].

With these considerations in mind, no discussion will be presented here concerning the assignment of a bonding geometry (bridged or terminal) of NO on $\operatorname{Pd}(111)$ or Pd(112). Instead, the coverage dependence and thermal behavior of the surface species yielding particular $\nu(\mathrm{N}-\mathrm{O})$ stretching frequencies will be used comparatively. In fact, the conclusions drawn in this report do not depend on the bonding geometry of NO on its adsorption site, but only on the adsorption site identity (terrace or step). The adsorption site, as inferred here by direct comparison of the $\nu(\mathrm{N}-\mathrm{O})$ modes observed by HREELS from $\mathrm{NO} / \mathrm{Pd}(111)$ and $\mathrm{NO} / \mathrm{Pd}(112)$, are also verified by a non-spectroscopic method (ESDIAD) in this report.

\subsection{1. $100 \mathrm{~K}$ adsorption: $N O / P d(111)$ and NO / Pd(112)}

Fig. 8 presents HREELS results recorded following $100 \mathrm{~K}$ exposure of $\mathrm{Pd}(111)$ to various amounts of NO. As can be seen in Fig. 8, low coverages of NO under these conditions produce a single $\nu(\mathrm{N}-\mathrm{O})$ mode which increases in frequency from 1535 to 
$1600 \mathrm{~cm}^{-1}$ as the NO coverage rises, followed by the appearance of another distinct $\nu(\mathrm{N}-\mathrm{O})$ vibrational feature at $1750 \mathrm{~cm}^{-1}$ at higher coverages. These observations from Fig. 8 are in agreement with the HREELS results of Bertolo and Jacobi [22], and Wickham et al. [24], and also with the infrared (IR) data of Chen and Goodman [25], all of which were recorded following $100 \mathrm{~K}$ adsorption of NO on Pd(111). In Fig. 8, spectra from many more NO coverages are presented than in Refs. [22] and [24]. The data of Fig. 8 will be used for direct comparison to HREELS data acquired from NO/Pd(112) under identical conditions.

The bottom half of Fig. 9 indicates that NO adsorbed on $\mathrm{Pd}(112)$ at $100 \mathrm{~K}$ at low coverage exhibits a $\nu(\mathrm{N}-\mathrm{O})$ mode at $1522 \mathrm{~cm}^{-1}$ which increases in frequency (to $1540 \mathrm{~cm}^{-1}$ ) as the NO coverage rises. The coverage dependence and frequency of this $\sim 1540 \mathrm{~cm}^{-1}$ mode in Fig. 9 is similar to that observed in Fig. 8 from NO/Pd(111) under identical conditions. This direct comparison between NO on $\mathrm{Pd}(111)$ and $\mathrm{Pd}(112)$ is used to assign the $\sim 1540 \mathrm{~cm}^{-1}$ vibrational feature of Fig. 9 to the $\nu(\mathrm{N}-\mathrm{O})$ mode of $\mathrm{NO}$ adsorbed on the (111) terrace sites of $\mathrm{Pd}(112)$ at low coverage.

As the NO exposure is slowly increased in the bottom half of Fig. 9, another $\nu(\mathrm{N}-\mathrm{O})$ mode near $1645 \mathrm{~cm}^{-1}$ is observed to increase in relative intensity and frequency. This $\sim 1645 \mathrm{~cm}^{-1}$ band is not observed under any adsorption conditions from NO/ Pd(111) (see Fig. 8 and Refs. [22,24,25]). In comparison, $\mathrm{Pd}(100)$ surfaces saturated by $\mathrm{NO}$ at $100 \mathrm{~K}$ and then annealed to $250 \mathrm{~K}$ (to remove weakly bound NO) exhibit a $\sim 1678 \mathrm{~cm}^{-1}$ mode using HREELS [27] and $\sim 1677 \mathrm{~cm}^{-1}$ mode using IR [25]. This $\nu(\mathrm{N}-\mathrm{O})$ band shifts even lower in frequency in the IR spectra (to $\sim 1655 \mathrm{~cm}^{-1}$ ) as the NO surface coverage is depleted further by annealing to $350 \mathrm{~K}$ [25]. In addition, low ( 0.06 langmuir) NO exposure at $80 \mathrm{~K}$ on $\mathrm{Pd}(100)$ produces a $\nu(\mathrm{N}-\mathrm{O})$ feature in HREELS at $1660 \mathrm{~cm}^{-1}$ [28]. With these results in mind, the $\sim 1645 \mathrm{~cm}^{-1}$ mode observed in the bottom half of Fig. 9 is assigned as the $\nu(\mathrm{N}-\mathrm{O})$ stretching frequency of NO adsorbed on the (001) step sites of $\operatorname{Pd}(112)$.

At the highest NO exposures on Pd(112) in Fig. 9, a $\sim 1738 \mathrm{~cm}^{-1} \nu(\mathrm{N}-\mathrm{O})$ band with a small shoulder near $1638 \mathrm{~cm}^{-1}$ is observed. Under similar conditions, high coverages of NO on $\mathrm{Pd}(111)$ produce HREELS bands near 1750 and $1600 \mathrm{~cm}^{-1}$ (see Fig. 8 and Refs. [22,24]). In addition, saturation of $\mathrm{Pd}(100)$ by $\mathrm{NO}$ at $80 \mathrm{~K}$ produces a broad $\sim 1720$ $\mathrm{cm}^{-1}$ feature in HREELS with a low frequency shoulder extending below $1500 \mathrm{~cm}^{-1}$ [28]. This same $\nu(\mathrm{N}-\mathrm{O})$ band seen by HREELS [28] appears in IR spectra (following $100 \mathrm{~K}$ NO saturation of $\operatorname{Pd}(100)$ ) as three modes near 1737, 1708, and 1695 $\mathrm{cm}^{-1}$ [25]. Upon consideration of these results, along with the possibility of through-bond and throughspace NO-NO coupling and intensity sharing between $\nu(\mathrm{N}-\mathrm{O})$ modes, the high exposure regime of Fig. 9 will simply be interpreted as resulting from the vibrations of a mixture of NO species adsorbed on both (111) terraces and (001) steps of Pd(112).

The most significant HREELS results presented in this section are that $\mathrm{NO}$ adsorption on $\mathrm{Pd}(111)$ and $\mathrm{Pd}(112)$ is molecular at $100 \mathrm{~K}$. Additionally, it is concluded that NO adsorption on $\operatorname{Pd}(112)$ at $100 \mathrm{~K}$ occurs preferentially at (111) terrace sites following low NO exposures and that (001) step sites are only populated by higher NO exposures.

\subsection{2. $373 \mathrm{~K}$ adsorption: $N O / P d(111)$ and NO $/ P d(112)$}

The spectra presented in Fig. 10 resulted from HREELS measurements from NO/Pd(111) following various $373 \mathrm{~K}$ NO exposures. Only one $\nu(\mathrm{N}-\mathrm{O})$ mode is observed in Fig. 10, exhibiting a frequency of $1540 \mathrm{~cm}^{-1}$ at low NO coverage which increases to $1590 \mathrm{~cm}^{-1}$ at high NO coverage. These results are in agreement with previous studies of NO/ Pd(111) by HREELS [22,24] and IR [25]. By direct comparison, the $\nu(\mathrm{N}-\mathrm{O})$ vibrational feature present in Fig. 10 is seen to be analogous to the low frequency $\nu(\mathrm{N}-\mathrm{O})$ mode observed in Fig. 8 following $100 \mathrm{~K}$ NO adsorption on $\mathrm{Pd}(111)$.

Low coverage adsorption of $\mathrm{NO}$ on $\mathrm{Pd}(112)$ at $373 \mathrm{~K}$ (bottom half of Fig. 11) produces vibrational spectra with only one $\nu(\mathrm{N}-\mathrm{O})$ band at $1535 \mathrm{~cm}^{-1}$, which shifts to $1550 \mathrm{~cm}^{-1}$ at higher NO exposures. By comparison with the data of Fig. 10, which was acquired from NO/Pd(111) under identical conditions, the low frequency mode observed in the bottom half of Fig. 11 is assigned to $\nu(\mathrm{N}-\mathrm{O})$ vibrations of NO adsorbed on (111) terrace sites of the Pd(112) surface. 
Another $\nu(\mathrm{N}-\mathrm{O})$ mode, assigned to NO adsorbed on (001) step sites, appears in Fig. 11 at $1655 \mathrm{~cm}^{-1}$ following an NO exposure of $6.9 \times 10^{14} \mathrm{~cm}^{-2}$. This assignment to (001) step sites is based on comparison of Fig. 11 with Fig. 10, where no equivalent $\nu(\mathrm{N}-\mathrm{O})$ mode is observed from $\mathrm{NO} / \mathrm{Pd}(111)$ under identical conditions. In addition, essentially the same behavior as seen in Figs. 10 and 11 for $T_{\text {ads }}=373 \mathrm{~K}$ is observed in HREELS data following low coverage NO adsorption on $\mathrm{Pd}(111)$ and $\mathrm{Pd}(112)$ at $100 \mathrm{~K}$ (Figs. 8 and 9 , respectively). Thus the same comparisons to previous $\mathrm{NO} / \mathrm{Pd}(100)$ vibrational studies $[25,27,28]$ presented in the discussion of Fig. 9 ( $\mathrm{Sec}-$ tion 4.2.1) are adopted here, further substantiating the assignment of the $1655 \mathrm{~cm}^{-1}$ band in Fig. 11 to $\nu(\mathrm{N}-\mathrm{O})$ modes of NO adsorbed on the (001) steps of $\mathrm{Pd}(112)$.

High NO exposures on $\mathrm{Pd}(112)$ at $373 \mathrm{~K}$ produce a broad $1670 \mathrm{~cm}^{-1}$ vibrational feature in the top spectra of Fig. 11, with a low frequency $(\sim 1550$ $\mathrm{cm}^{-1}$ ) shoulder. This broad $\nu(\mathrm{N}-\mathrm{O})$ feature results from a mixture of NO species, adsorbed at both (111) terraces and (001) steps of the Pd(112) surface.

The important conclusions drawn from the HREELS data of this section are that adsorption of $\mathrm{NO}$ on $\mathrm{Pd}(111)$ and $\mathrm{Pd}(112)$ at $373 \mathrm{~K}$ is molecular. In addition, NO has been shown to preferentially adsorb at low coverages on the (111) terrace sites of $\operatorname{Pd}(112)$ at $373 \mathrm{~K}$, and to occupy the (001) step sites of this surface only at higher NO coverages.

The HREELS observation that NO adsorbs on $\mathrm{Pd}(112)$ at both 100 and $373 \mathrm{~K}$ in the same site-filling sequence (terrace followed by step) indicates that terrace-NO contains a weaker $\mathrm{N}-\mathrm{O}$ bond than step $\mathrm{N}-\mathrm{O}$. This interpretation is consistent with the fact that terrace-bound $\mathrm{NO}$ on $\mathrm{Pd}(112)$ exhibits a $\nu(\mathrm{N}-\mathrm{O})$ frequency $\left(1520-1550 \mathrm{~cm}^{-1}\right)$ which is lower than that associated with step-site NO (1641-1655 $\left.\mathrm{cm}^{-1}\right)$. According to the general statements made in the prologue (Section 4.2), a lower $\nu(\mathrm{N}-\mathrm{O}$ ) frequency implies a weaker $\mathrm{N}-\mathrm{O}$ bond. Thus the molecular adsorption of NO on $\operatorname{Pd}(112)$ follows a self-consistent yet counter-intuitive site-filling sequence.

\subsubsection{Thermal dissociation: $N O / P d(111)$ and $N O / P d(112)$}

The HREELS data of Fig. 12 werc recorded following a large NO exposure on $\mathrm{Pd}(111)$ at $373 \mathrm{~K}$ and subsequent stepwise annealing. As the annealing temperature in Fig. 12 increases, the frequency of the $\nu(\mathrm{N}-\mathrm{O})$ mode decreases from 1585 to $1535 \mathrm{~cm}^{-1}$, indicative of the lowering of the NO surface coverage via thermal desorption.

The most important feature of Fig. 12 is the appearance of a $\nu(\mathrm{Pd}-\mathrm{O})$ mode near $525 \mathrm{~cm}^{-1}$ with a shoulder near $700 \mathrm{~cm}^{-1}$ at an annealing temperature of $490 \mathrm{~K}$. Banse and Koel observed a broad HREELS feature at $510 \mathrm{~cm}^{-1}$, with shoulders near 425,675 , and $715 \mathrm{~cm}^{-1}$, following the deposition of atomic oxygen on $\operatorname{Pd}(111)$ via the dissociative adsorption of $\mathrm{NO}_{2}$ at $530 \mathrm{~K}$ [40]. Additionally, roomtemperature $\mathrm{O}_{2}$ adsorption on $\mathrm{Pd}(111)$ (to produce $\mathrm{O} / \mathrm{Pd}(111)$ ) yields a vibrational spectrum exhibiting a strong $\nu(\mathrm{Pd}-\mathrm{O})$ mode at $485 \mathrm{~cm}^{-1}$ with weaker structure at 715 and $818 \mathrm{~cm}^{-1}$, as observed by Imbihl and Demuth using HREELS [41].

Thus the weak 525 and $700 \mathrm{~cm}^{-1}$ vibrational features observed in Fig. 12 are interpreted as resulting from $O(a)$, deposited on the $\operatorname{Pd}(111)$ surface by the decomposition of a small amount of NO during heating to $490 \mathrm{~K}$. Annealing to $550 \mathrm{~K}$ was sufficient to remove these Pd-O features from the HREELS data, presumably due to the diffusion of this surface-bound $\mathrm{O}$ into the Pd bulk. These two conclusions are consistent with the TPD results discussed above, which indicated that small amounts of NO thermally dissociate on $\mathrm{Pd}(111)$ upon heating and deposit $\mathrm{O}$ on the surface, as evidenced by the observation of $\mathrm{N}_{2}$ and $\mathrm{N}_{2} \mathrm{O}$, but not $\mathrm{O}_{2}$ or $\mathrm{NO}_{2}$ thermal desorption species. It is possible that the presence of a small percentage of defect sites on the $\operatorname{Pd}(111)$ surface is responsible for these minimal amounts of NO decomposition.

Fig. 13 presents the results of an HREELS investigation of the thermal behavior of a high coverage of NO adsorbed on $\mathrm{Pd}(112)$ at $373 \mathrm{~K}$. Annealing to $460 \mathrm{~K}$ in Fig. 13 removes the NO adsorbed at the step sites of $\mathrm{Pd}(112)$ via thermal desorption, leaving only terrace-bound NO in the molecular form. Note that no evidence is seen in the bottom two spectra of Fig. 13 that would indicate the dissociation of stepsite NO on Pd(112) below $460 \mathrm{~K}$. It is seen that annealing to $490 \mathrm{~K}$ induces the decomposition of terrace-bound NO, evidenced by the appearance of a $\nu(\mathrm{Pd}-\mathrm{O})$ feature of surface-bound $\mathrm{O}$ at $500 \mathrm{~cm}^{-1}$ in Fig. 13. In addition, the intensity of a $1000 \mathrm{~cm}^{-1}$ 
mode is seen to rise, then fall, in Fig. 13 in the range $490 \leqslant T \leqslant 520 \mathrm{~K}$. This $1000 \mathrm{~cm}^{-1}$ band is assigned to $\mathrm{Pd}-\mathrm{O}$ vibrations of $\mathrm{O}$ incorporated within the near-surface region of $\mathrm{Pd}(112)$, and will be discussed below. Both of these $\mathrm{O}$-related vibrational features disappear following $550 \mathrm{~K}$ annealing, presumably due to absorption of the oxygen by the Pd bulk.

The HREELS data of Fig. 14 were recorded following low coverage adsorption of NO on Pd(112) at $373 \mathrm{~K}$. In Fig. 14, exclusive $\mathrm{NO}$ adsorption on (111) terrace sites is indicated by the $1525 \mathrm{~cm}^{-1}$ $\nu(\mathrm{N}-\mathrm{O})$ band (bottom spectrum). As the annealing temperature reaches $490 \mathrm{~K}$, surface-bound $\mathrm{O}(520$ $\left.\mathrm{cm}^{-1}\right)$ and sub-surface $\mathrm{O}\left(990 \mathrm{~cm}^{-1}\right)$ vibrational modes are observed in Fig. 14, which increase and then decrease in relative intensity as the temperature rises. These results indicate that low coverage (terrace-bound) NO partially dissociates on $\mathrm{Pd}(112)$ at $490 \mathrm{~K}$, leaving $\mathrm{O}$ at the surface. Both of these $\mathrm{O}$ species dissolve into the Pd bulk following $550 \mathrm{~K}$ annealing, as evidenced by the disappearance of the $\mathrm{Pd}-\mathrm{O}$ modes in the vibrational spectra.

One major conclusion of this section is that surface-bound $O$ is formed as a product of NO dissociation on both $\operatorname{Pd}(111)$ and $\operatorname{Pd}(112)$. This $O(a)$ produces a $\nu(\mathrm{Pd}-\mathrm{O})$ mode in the frequency range 500 $525 \mathrm{~cm}^{-1}$, which appears at an annealing temperature of $490 \mathrm{~K}$ and disappears upon annealing to 550 $\mathrm{K}$, following the thermal dissociation of NO on both surfaces. The dissolution of $O(\mathrm{a})$ into the Pd bulk is presumably responsible for this latter observation.

Another significant point stressed in this section is that sub-surface $\mathrm{O}\left(\nu(\mathrm{Pd}-\mathrm{O}) \approx 1000 \mathrm{~cm}^{-1}\right)$ is observed by HREELS only on $\mathrm{Pd}(112)$, and not on Pd(111), as a product of NO thermal dccomposition. Similar behavior was observed in this study for dissociative $\mathrm{O}_{2}$ adsorption; $\mathrm{O} / \mathrm{Pd}(111)$ produces one vibrational mode $\left(\sim 500 \mathrm{~cm}^{-1}\right)$ whereas $\mathrm{O} / \mathrm{Pd}(112)$ produces two modes $\left(\sim 500\right.$ and $\left.\sim 1000 \mathrm{~cm}^{-1}\right)$. It is possible that the (001) steps on $\mathrm{Pd}(112)$ provide a low energy pathway which allows $O$ to easily penetrate into and to remain in the near-surface region below $550 \mathrm{~K}$.

The final important observation in this section is based on comparison of the relative intensities of the $\nu(\mathrm{N}-\mathrm{O})$ modes to those of the $\mathrm{Pd}-\mathrm{O}$ modes in the spectra of Figs, 13 (high initial NO coverage) and 14 (low initial NO coverage) following annealing to
$490-510 \mathrm{~K}$. This comparison indicates that relatively more $O$ is present in Fig. 14 than in Fig. 13 compared to NO, which indicates that a larger fraction of the NO decomposed at the lower initial NO coverage. This observation is entirely consistent with the TPD results summarized in Fig. 7, where the relative yields of $\mathrm{N}_{2}$ and $\mathrm{N}_{2} \mathrm{O}$ were largest at the lowest $\mathrm{NO}$ exposures. This conclusion, drawn from both TPD and HREELS results, indicates that coverage-dependent inter-particle interactions play a major role in determining the fate of $\mathrm{NO}$ adsorbed on $\mathrm{Pd}(112)$ upon heating. Under high coverage conditions where NO-NO repulsions are significant, NO desorption is favored over NO decomposition on $\operatorname{Pd}(112)$.

\subsection{4. $\mathrm{O}_{2} / \mathrm{Pd}(112)$}

The HREELS results obtained in this study following the dissociative adsorption of $\mathrm{O}_{2}$ on $\mathrm{Pd}(111)$ are consistent with previous HREELS studies of $\mathrm{O} / \mathrm{Pd}(111)[40,41]$ and thus are not presented. However, two results important to this paper concerning the presence of atomic oxygen on $\mathrm{Pd}(112)$ are discussed in this section. These are (1) the formation of sub-surface $O$ on $\operatorname{Pd}(112)$, and (2) the lack of preferential site blocking (toward NO adsorption) by oxygen atoms on $\mathrm{Pd}(112)$.

First of all, the absorption of $\mathrm{O}$ into $\mathrm{Pd}$ is a well-known phenomenon $[17,21,23,28,40-44]$, and presumably only a small energy barrier exists between the adsorption of $\mathrm{O}$ on a Pd surface and the incorporation of $\mathrm{O}$ below the first Pd layer. However, the presence of an O-related HREELS mode near $1000 \mathrm{~cm}^{-1}$ following $\mathrm{NO}$ or $\mathrm{O}_{2}$ thermal decomposition on $\mathrm{Pd}(112)$, and not on $\mathrm{Pd}(111)$, is interesting. This result for $\mathrm{Pd}(112)$ is shown in Fig. 15 , where low exposures of NO (left-hand side) and $\mathrm{O}_{2}$ (right-hand side) at $373 \mathrm{~K}$ were performed, followed by stepwise annealing. Although the relative intensities of the $O(a)$ mode $\left(\sim 500 \mathrm{~cm}^{-1}\right)$ and sub-surface $O$ mode $\left(\sim 1000 \mathrm{~cm}^{-1}\right)$ differ following $\mathrm{NO}$ and $\mathrm{O}_{2}$ dissociation, it is evident from Fig. 15 that both of these modes are O-related. In addition, both of these vibrational features exhibit the same thermal behavior whether produced from $\mathrm{NO}$ or $\mathrm{O}_{2}$, falling below the HREELS noise level above an annealing temperature of $550 \mathrm{~K}$ in Fig. 15 .

Sub-surface $O$ formation has been proposed as a 
possible explanation of anomalously high frequency O-related HREELS features observed from other transition metal surfaces $[45,46]$. Annealing $\mathrm{Ni}(111)$ [45] or $\mathrm{Rh}(110)$ [46] surfaces exposed to $\mathrm{O}_{2}$ at low temperatures resulted in (presumably sub-surface $\mathrm{O}$ ) HREELS bands near 970 and $984 \mathrm{~cm}^{-1}$, respectively. In addition, heating $\mathrm{NO} / \mathrm{Ni}(111)$ to $700 \mathrm{~K}$, which liberated $\mathrm{N}_{2}(\mathrm{~g})$ and deposited $\mathrm{O}$ at the surface, produced an HREELS mode near $980 \mathrm{~cm}^{-1}$, possibly indicative of the presence of sub-surface $O$ [45].

These literature results $[45,46]$, in conjunction with the data of Fig. 15, indicate that the $\sim 1000$ $\mathrm{cm}^{-1}$ HREELS mode observed in this study following NO thermal dissociation on $\mathrm{Pd}(112)$ (Figs. 1315 ) is produced by sub-surface $O$ species. The $a b-$ sence of such modes on $\mathrm{Pd}(111)$ (Fig. 12) implies that the (001) steps on the Pd(112) surface act as an efficient channel for $O$ penetration into the nearsurface region. Of course, more $O$ is probably present on $\mathrm{Pd}(112)$ than on $\mathrm{Pd}(111)$ following NO thermal decomposition under similar conditions, because of the enhanced reactivity of $\mathrm{Pd}(112)$ toward dissociating NO. However, $\mathrm{O}$ deposition on $\mathrm{Pd}(111)$ via $\mathrm{O}_{2}$ exposure, under conditions similar to that employed for the results shown in the right-hand side of Fig. 15, yielded no $\sim 1000 \mathrm{~cm}^{-1}$ vibrational modes. Thus it seems that, independent of the amount of atomic oxygen available at the surfaces, $\operatorname{Pd}(112)$ forms both sub-surface and surface-bound $O$ species, whereas only $\mathrm{O}(\mathrm{a})$ is formed on $\mathrm{Pd}(111)$.

Fig. 16 indicates that the pre-adsorption of atomic oxygen on Pd(112) does not preferentially block the step sites toward NO adsorption. As cvident in Fig. $16,373 \mathrm{~K}$ adsorption of NO on clean (right-hand side) and $\mathrm{O}$ pre-covered (left-hand side) $\mathrm{Pd}(112)$ produces essentially the same two $\nu(\mathrm{N}-\mathrm{O})$ modes following virtually identical NO exposures. Low coverages of NO adsorb on the (111) terrace sites of Pd(112) (bottom two spectra) whereas both terraces and steps are occupied by $\mathrm{NO}$ at higher coverages (top two spectra) in Fig. 16. Therefore, the site-filling sequence of $\mathrm{NO}$ on $\mathrm{Pd}(112)$ observed in this study occurs regardless of the presence of $O$ on the surface. Generally speaking, intuition would lead to the prediction that $\mathrm{O}$ will preferentially poison the step sites for NO adsorption, but this intuitive prediction is not supported by the data of Fig. 16. Possibly the adsorption of NO at the top of a step is not influenced by the adsorption of $\mathrm{O}$ in the high coordination site at the bottom of a step.

\subsection{Electron stimulated desorption ion angular distributions}

The ESD behavior of NO adsorbed on W [47], Si $[48,49]$, Ni [50-54], and Pt [55-58] surfaces has been studied previously; however NO/Pd systems have not been investigated by ESD methods to our knowledge [59]. Therefore, an appendix containing several experimental details about ESD from NO/ $\mathrm{Pd}(111)$ is included at the end of this report. The results shown in the Appendix may be useful to workers in the ESD field, but do not affect any conclusions about the surface chemistry of $\mathrm{NO} / \mathrm{Pd}$ drawn in the main body of this paper.

The ESDIAD technique is based on the measurement of the real-space distribution of particles desorbed from a surface during electron bombardment. From the 'initial-state' viewpoint, the observed ESDIAD patterns from these desorbing particles represent a statistical average over the instantaneous directions of the original chemical bonds ruptured by the ESD process [59]. In addition, the measured angular distributions may deviate from initial-state expectations due to the presence of anisotropic 'final-state' effects, which can act on the desorbing particles en-route to the detector [59-61]. However, the major conclusions presented in this section (based on initial-state concepts) are entirely consistent with the HREELS data discussed above, and thus finalstate contributions to the ESDIAD patterns are considered to be of secondary importance.

In order to observe the angular distributions of $\mathrm{O}^{+}$ions from $\mathrm{NO} / \mathrm{Pd}$ in a manner which should most directly reflect the $\mathrm{N}-\mathrm{O}$ bond orientations at the surface, the ESDIAD patterns presented here were acquired under field-free conditions. Applying a positive bias to the crystal (with respect to the detector) is frequently used in many studies to enhance the positive ion counting rate, but this approach would modify the angular information required in this study. Because of the contribution of a large $X$-ray background at electron energies $\geqslant 800$ $\mathrm{eV}$, the signal-to-noise ratios of the ESDIAD patterns shown in this report are lower than usually seen in the literature [59]. 


\subsection{1. $N O / P d(111)$}

All of the ESDIAD patterns recorded following NO adsorption at $300 \mathrm{~K}$ on Pd(111) consisted of a single $\mathrm{O}^{+}$beam centered about the $\langle 111\rangle$ surface normal (see Figs. 17 and 18, where the NO exposure increases from (a)-(d)). In addition, the measured HWHM of these $\mathrm{O}^{+}$ESDIAD patterns does not strongly depend on the NO surface coverage (see Fig. 20). Although not shown here, essentially the same behavior was observed following $100 \mathrm{~K}$ NO adsorption on $\mathrm{Pd}(111)$, which yielded an $\mathrm{O}^{+}$beam normal to the surface with a HWHM of $\sim 6^{\circ}$ in ESDIAD measurements. The major conclusions based on these observations are that NO remains upright on $\operatorname{Pd}(111)$ up to saturation coverages following adsorption in the temperature range 100-300 $K$, and that no evidence for tilted NO species on $\mathrm{Pd}(111)$ has been observed in this study. This interpretation is consistent with the angular-resolved ultra-violet photoelectron spectroscopy (ARUPS) study of Bertolo and Jacobi [22], where it was concluded that adsorbed NO remains basically perpendicular on $\operatorname{Pd}(111)$ at all coverages.

The data of Fig. 19 indicates that the total $\mathrm{O}^{+}$ yield from $\mathrm{NO} / \mathrm{Pd}(111)$ increases monotonically with NO exposure, tending to saturate at high NO coverage. In Fig. 19, the monotonic rise of the $\mathrm{O}^{+}$ yield with NO exposure indicates that no ESDIAD evidence is found in this study for the presence of a minority of NO species (such as those adsorbed at random defect sites) which might possibly exhibit anomolously high ESD cross-sections $[62,63]$. The saturation behavior at high NO exposures is interpreted as resulting from the filling of the $\mathrm{Pd}(111)$ surface by $\mathrm{NO}$ adsorbed at $300 \mathrm{~K}$, and no indication of strong intermolecular electronic quenching effects is seen in Fig. 19 [64].

\subsection{2. $N O / P d(112)$}

Figs. 21 and 22 clearly indicate that as the NO exposure rises at $300 \mathrm{~K}$ (from (a)-(d) in these figures), the ESDLAD patterns from NO/Pd(112) consisting of a single $\mathrm{O}^{+}$beam at low coverages transform into two-beam patterns at larger NO exposures. The same sequence was observed at different adsorption temperatures (100 and $373 \mathrm{~K})$. In all cases, the single $\mathrm{O}^{+}$beam from low coverages of
$\mathrm{NO} / \mathrm{Pd}(112)$ is located near $\left(+14^{\circ}, 0^{\circ}\right)$ in the resulting ESDIAD patterns, close to the direction of the $\langle 111\rangle$ terrace normal $\left(+19.5^{\circ}, 0^{\circ}\right)$. These results, combined with the HREELS data of Figs. 9 and 11, strongly indicate that NO preferentially adsorbs on the (111) terraces of $\operatorname{Pd}(112)$ at low coverages for adsorption temperatures in the 100-373 $\mathrm{K}$ range.

The appearance of a second $\mathrm{O}^{+}$beam in the ESDIAD patterns (at an NO exposure of $6.0 \times 10^{14}$ $\mathrm{cm}^{-2}$ in Figs. 21c and 22c) oriented in the downstairs direction near $\left(-16^{\circ}, 0^{\circ}\right)$ is indicative of the presence of NO on the step sites of $\operatorname{Pd}(112)$. The relative intensity of the downstairs-directed beam increases as the NO coverage rises further (see Figs. $21 \mathrm{~d}$ and $22 \mathrm{~d}$ ), indicating the increased occupation of step sites by NO. In these higher coverage ESDIAD patterns, the $\mathrm{O}^{+}$beam associated with terrace-bound NO appears near $\left(+16^{\circ}, 0^{\circ}\right)$, shifted slightly closer to the expected $\langle 111\rangle$ direction than in the low coverage measurements.

Since the Pd(112) surface has a large step density, the local electron density distribution and the local electric field strength at the surface will be highly anisotropic $[60,65-68]$. The $\mathrm{O}^{+}$ions desorbed from NO/Pd(112) via ESD will experience this non-uniform electric field as they escape from the surface. This final-state effect is believed to be responsible for the deflection of the measured $\mathrm{O}^{+}$beam slightly away from the expected $\langle 111\rangle$ direction for the terrace-bound NO. The possible presence of finalstate effects in ESDIAD does not alter the major conclusion of this section, which is that NO adsorbs preferentially on the terrace sites of $\mathrm{Pd}(112)$ at low coverages in the temperature range $100-373 \mathrm{~K}$, and only occupies the step sites at higher coverages.

\subsubsection{Role of step sites in NO dissociation on $\mathrm{Pd}$}

The enhanced capability of stepped $\operatorname{Pd}(112)$ to dissociate chemisorbed NO is a key finding of this work. This enhanced dissociation occurs in response to the presence of step sites, but not because of preferential NO occupation of the step sites. There are a number of different ways to explain this unusual phenomenon and some are listed below while being schematically diagrammed in Fig. 23. It is not possible in this work to discriminate between the following three possibilities. 


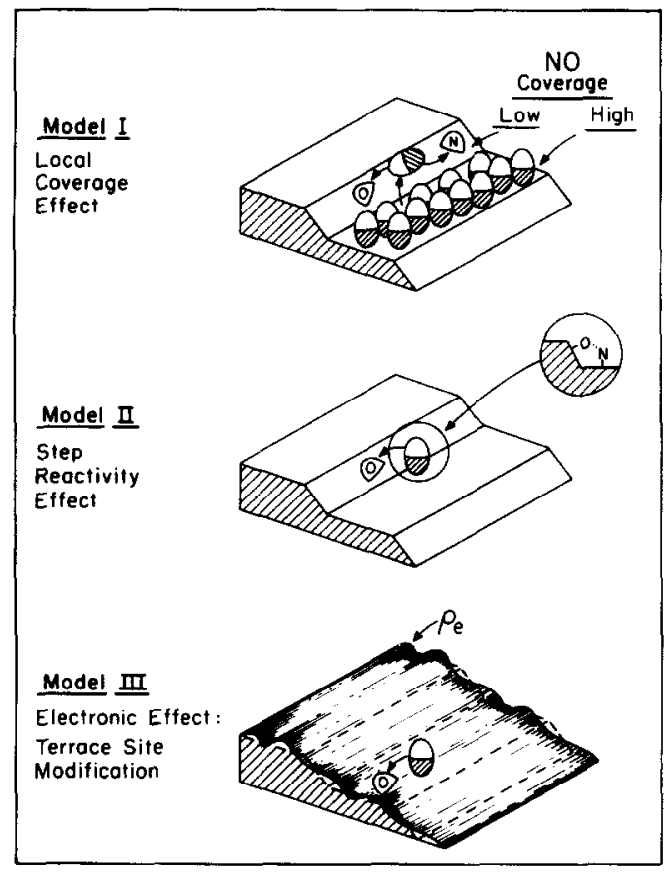

Fig. 23. Three possible mechanisms for preferential NO dissociation on $\operatorname{Pd}(112)$. These ideas are discussed in the text.

\section{Model I. Local coverage effects}

Our results suggest that the bonding of NO occurs preferentially on the terrace sites of $\operatorname{Pd}(112)$ due to stronger chemisorption on these sites. At the NO dissociation temperature near $500 \mathrm{~K}$, the NO coverage will be high on the terrace sites and low on the step sites. In this model, then, a migrating NO molecule which happens to find itself on a step site will expcrience the presencc of empty neighbor sites, promoting dissociation at low local coverages for steric reasons, in agreement with the model of Davies and Lambert [11].

\section{Model II. Step reactivity effects}

In this model, an NO molecule chemisorbed on a (111) terrace site may be able to sterically place the oxygen moiety favorably near a step Pd atom, promoting dissociation by strong bonding of both $\mathrm{O}$ and $\mathrm{N}$ to $\mathrm{Pd}$ atoms.

Model III. Electronic effect: terrace site modification

It is well known that charge density $\left(\rho_{\mathrm{e}}\right)$ variations due to step sites on metals extend into the terrace regions $[65,68,69]$.
The electronic modification of the terrace sites due to this charge redistribution in the vicinity of the step sites may be responsible for the enhanced dissociation of NO on the terrace sites, and hence the increased activity of $\mathrm{Pd}(112)$ compared to $\mathrm{Pd}(111)$.

\section{Conclusions}

This report has presented a detailed comparison of NO adsorbed on $\mathrm{Pd}(111)$ and $\mathrm{Pd}(112)$ surfaces. The following results are found:

(1) NO adsorption on $\mathrm{Pd}(111)$ and $\mathrm{Pd}(112)$ is molecular in the temperature range $100-373 \mathrm{~K}$.

(2) NO adsorbs upright on $\mathrm{Pd}(111)$ at all coverages, and no evidence for tilted NO species is observed.

(3) NO adsorbs at higher coverages in an inclined manner on $\operatorname{Pd}(112)$, with the $\mathrm{N}-\mathrm{O}$ bond oriented in the downstairs direction.

(4) Upon heating, NO predominantly desorbs molecularly from $\operatorname{Pd}(111)$ near $500 \mathrm{~K}$, with an activation energy and pre-exponential factor for desorption which strongly depend on the NO surface coverage. This indicates that coverage-dependent repulsive interactions between adsorbed NO molecules occur on $\operatorname{Pd}(111)$.

(5) Upon heating, relatively large amounts of $\mathrm{N}_{2}$ and $\mathrm{N}_{2} \mathrm{O}$, in addition to $\mathrm{NO}$, desorb from $\mathrm{NO} /$ $\operatorname{Pd}(112)$ in the temperature range $450-550 \mathrm{~K}$. This indicates that the stepped $\operatorname{Pd}(112)$ surface is more active toward NO dissociation than the flat $\operatorname{Pd}(111)$ planc. However, preferential NO adsorption on the step sites of $\mathrm{Pd}(112)$ is not found, and cannot be responsible for the activity of the stepped surface toward NO decomposition.

(6) The fractional amount of NO decomposition upon heating is largest for the lowest NO coverages on $\mathrm{Pd}(112)$, irrespective of the fact that NO preferentially adsorbs on the (111) terrace sites of Pd(112) under these conditions.

(7) NO adsorption occurs preferentially on the (111) terraces of $\operatorname{Pd}(112)$ following adsorption in the temperature range 100-373 K, filling the (001) step sites only at higher coverages. This indicates that terrace-NO is more strongly bound to $\mathrm{Pd}(112)$ than step-NO. This observation is also an indication that NO is initially mobile on the surface, and is able to 
seek out the strongest binding sites before being trapped.

(8) Vibrational modes of surface-bound $O$ are observed following annealing of $\mathrm{NO} / \mathrm{Pd}(111)$ to $490 \mathrm{~K}$. This indicates that a small amount of NO dissociation occurs, possibly due to the presence of defect sites.

(9) Surface-bound $O$ and sub-surface $O$ vibrational modes are observed following annealing of $\mathrm{NO} / \mathrm{Pd}(112)$ to $490 \mathrm{~K}$, also indicating the thermal decomposition of NO. The presence of the (001) steps is believed to be responsible for the formation of sub-surface $\mathrm{O}$ on $\mathrm{Pd}(112)$, offering an efficient pathway for $O$ incorporation within the near-surface region.

(10) Dissociative $\mathrm{O}_{2}$ adsorption on $\mathrm{Pd}(111)$ and Pd(112) verified the exclusive formation of surfacebound $\mathrm{O}$ on $\operatorname{Pd}(111)$ and the presence of both surface and sub-surface $O$ vibrational modes on $\mathrm{Pd}(112)$.

(11) Annealing to $550 \mathrm{~K}$ induces the diffusion of both surface-bound $\mathrm{O}(\operatorname{Pd}(111) ; \operatorname{Pd}(112))$ and subsurface $\mathrm{O}(\mathrm{Pd}(112))$ into the Pd bulk.

(12) The pre-adsorption of $O$ on Pd(112) does not preferentially block either the step or the terrace sites toward NO adsorption.

\section{Appendix}

The experimental results presented in this Appendix provide details about the ESD behavior of $\mathrm{NO} / \mathrm{Pd}$ that are not directly pertinent to the main conclusions of this paper. However, since this is the first detailed ESD study of NO/Pd systems to our knowledge [59], these results are included for completeness.

Fig. 24 shows that the only positive ion detected during ESD from $\mathrm{NO} / \mathrm{Pd}$ in this study was $\mathrm{O}^{+}$. Following adsorption of $\mathrm{NO}$ at $300 \mathrm{~K}\left(8.9 \times 10^{14}\right.$ $\mathrm{cm}^{-2}$ ) on clean $\mathrm{Pd}(111)$, the surface was cooled to $100 \mathrm{~K}$. The crystal was then positioned in front of the QMS (as for TPD, but with the QMS ionizer turned off) and was bombarded by electrons from an electron gun $\left(E_{\mathrm{i}}=900 \mathrm{eV}, I=8.8 \mu \mathrm{A}\right)$. The positive ions desorbed via ESD from the NO-covered Pd surface entered the QMS and were detected as shown in Fig. 24. A grid mounted in front of the QMS cage was biased negatively (with respect to the crystal) by

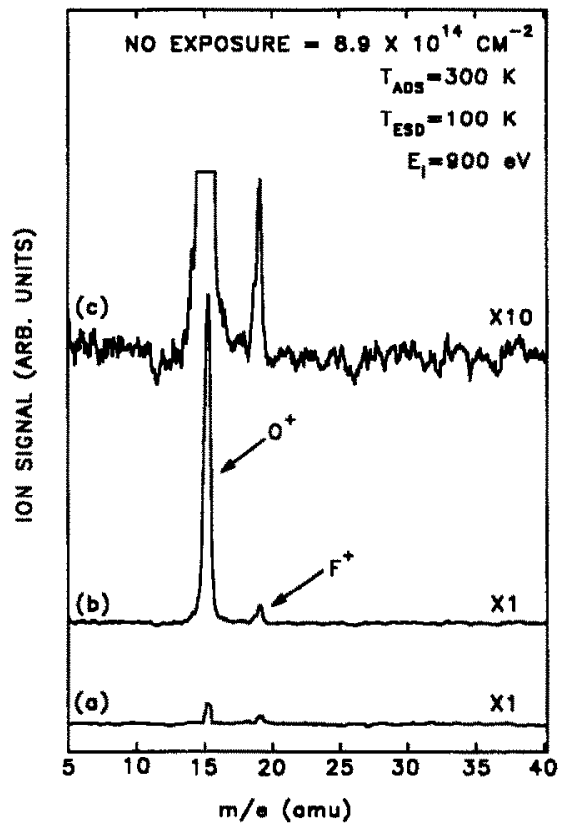

Fig. 24. Mass spectral identification of $\mathrm{O}^{+}$as the only detectable positive ion desorbed during electron stimulated desorption from NO/Pd(111). Following NO exposure $\left(\epsilon=8.9 \times 10^{14} \mathrm{~cm}^{-2}\right)$ at $300 \mathrm{~K}$, the $\mathrm{Pd}(111)$ surface was cooled to $100 \mathrm{~K}$, where spectra (b) and (c) were recorded. The surface was then annealed to 1200 $\mathrm{K}$ to desorb NO, and cooled back to $100 \mathrm{~K}$ for acquisition of spectrum (a). The spurious $\mathrm{F}^{+}$signal originates from the electron gun itself, and the electron beam energy was $900 \mathrm{eV}$.

$\sim 3 \mathrm{~V}$, in order to focus the positive ions into the QMS. It should be noted that a different electron gun than the one employed here for ion identification is used for ESDIAD data acquisition.

The mass spectra of Figs. $24 b$ and $24 c$ were recorded immediately after NO adsorption at $300 \mathrm{~K}$ and cooling of the crystal to $100 \mathrm{~K}$. The crystal was then flash annealed to $1200 \mathrm{~K}$ to desorb the NO and was allowed to cool back to $100 \mathrm{~K}$, where the data of Fig. $24 \mathrm{a}$ were recorded. As can be seen, $\mathrm{O}^{+}$is the major positive ion detected from the NO-covered $\mathrm{Pd}$ surface, and no evidence for $\mathrm{N}^{+}, \mathrm{NO}^{+}$, or $\mathrm{O}^{2+}$ is observed in Fig. 24.

The spurious $\mathrm{F}^{+}$signal seen in Fig. 24 was observed to decrease in intensity with an increase in the time that the electron gun was operated, independent of whether the gun was focused on the crystal surface during that time. This indicates that the $\mathrm{F}^{+}$ signal arises from the electron gun itself, and not 
from the Pd surface [70]. This effect can be seen even in Fig. 24, where $\sim 30$ min elapsed after acquisition of Fig. $24 \mathrm{~b}$ and before the recording of Fig. 24a. Accordingly, the $\mathrm{F}^{+}$intensity in the latter spectrum is $\sim 1 / 3$ that of the former, due to the 'outgassing' of the electron gun during the $\sim 30 \mathrm{~min}$ delay.

Fig. 25 shows the dependence of the $\mathrm{O}^{+}$ion intensity from $\mathrm{NO} / \mathrm{Pd}(111)$ on the primary electron beam energy (uncorrected for work function differences). The clean $\mathrm{Pd}(111)$ surface was exposed to $7.3 \times 10^{14} \mathrm{NO} / \mathrm{cm}^{-2}$ at $300 \mathrm{~K}$, followed by cooling to $100 \mathrm{~K}$. ESDIAD patterns were recorded for different $E_{\mathrm{i}}$, with $I$ held constant at $3.0 \mathrm{nA}$. In addition, a positive bias of $30 \mathrm{~V}$ was applied to the crystal to focus the $\mathrm{O}^{+}$ions into a sharp spot at the center of the resulting ESDIAD patterns. The maximum number of counts observed in this centrally compressed $\mathrm{O}^{+}$ESDLAD spot versus $E_{\mathrm{i}}$ is plotted in Fig. 25, where the $+30 \mathrm{~V}$ bias on the crystal has been added to the value of $E_{\mathrm{i}}$ in each case. The different data

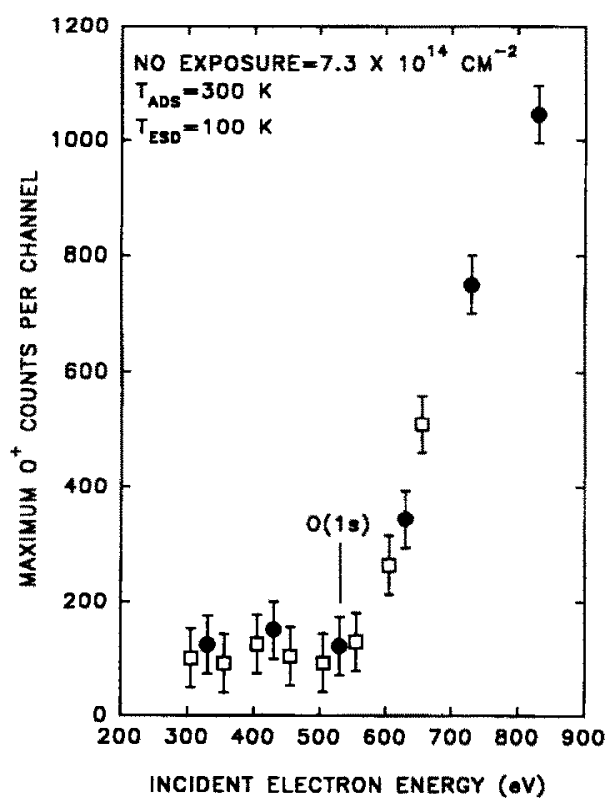

Fig. 25. Threshold measurement indicating that the $\mathrm{O}^{+}$yield from $\mathrm{NO} / \mathrm{Pd}(111)$ is first detected at $\sim 30 \mathrm{eV}$ above the energy of the $O(1 \mathrm{~s})$ core level. An NO exposure of $7.3 \times 10^{14} \mathrm{~cm}^{-2}$ at $300 \mathrm{~K}$ was employed in two separate experiments, indicated by the filled circles and the open squares. No normalization of the two data sets or corrections for work function differences were performed.

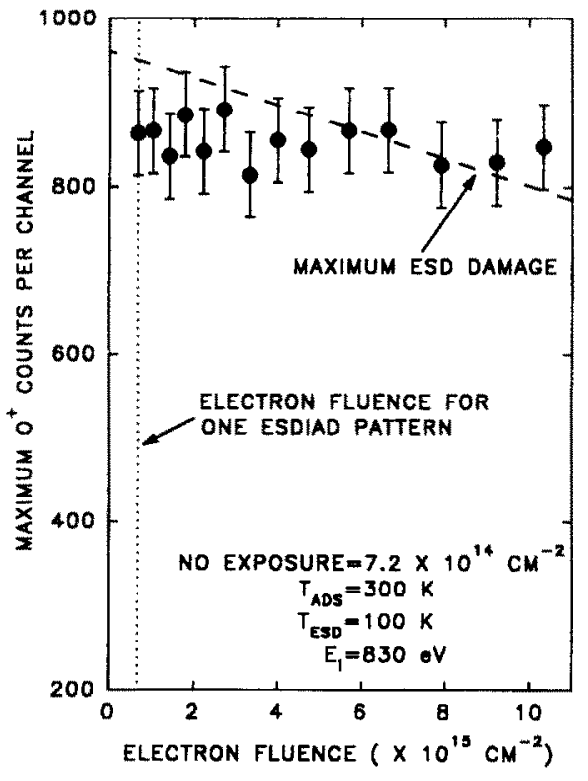

Fig. 26. The dependence of the $\mathrm{O}^{+}$intensity from $\mathrm{NO} / \mathrm{Pd}(111)$ on the electron fluence employed for electron stimulated desorption measurements. It can be seen that within detection limits, essentially no change in the $\mathrm{O}^{+}$intensity occurs during the acquisition of one ESDLAD data set. An NO exposure of $7.2 \times 10^{14}$ $\mathrm{cm}^{-2}$ was employed at $300 \mathrm{~K}$, and the data were collected at an incident electron energy of $830 \mathrm{eV}$.

points (closed circles and open squares) resulted from two independent sets of measurements, indicating that the \pm 50 count error bars shown in Fig. 25 are reasonable.

As clearly seen in Fig. 25, a threshold for the enhancement of the $\mathrm{O}^{+}$ion intensity occurs $\sim 30$ $\mathrm{eV}$ higher than the $\mathrm{O}(1 \mathrm{~s})$ core level, the position of which is roughly indicated in Fig. 25. This observation is consistent with other studies of NO adsorbed on metal surfaces [51-53,55], where this energy threshold was attributed to $\mathrm{O}(1 \mathrm{~s})$ ionization combined with a single shake-off process.

In order to estimate the relative amount of ESD damage occurring during the acquisition of one ESDIAD pattern, the data of Fig. 26 are presented. Here, NO $\left(7.2 \times 10^{14} \mathrm{~cm}^{-2}\right)$ was adsorbed on $\operatorname{Pd}(111)$ at $300 \mathrm{~K}$, after which the crystal was cooled to $100 \mathrm{~K}$. The electron gun energy and crystal current were fixed at $800 \mathrm{eV}$ and $4.2 \mathrm{nA}$, respectively, and ESDIAD patterns were recorded as a function of time. $\mathrm{A}+30 \mathrm{~V}$ bias was applied to the crystal (therefore $E_{\mathrm{i}}=830 \mathrm{eV}$ ) and the maximum counts in 
the central $\mathrm{O}^{+}$beam $( \pm 50$ counts) are shown in Fig. 26 versus the calculated electron fluence.

It can be seen from Fig. 26 that, within detection limits, little change in the $\mathrm{O}^{+}$intensity occurs. The vertical dotted line indicates the maximum electron fluence that the surface is exposed to during the collection of one ESDIAD pattern (including electron beam focusing and other experimental adjustments). The dashed line indicates the worst-case scenario, in which the maximum amount of detectable ESD damage to adsorbed NO would occur viewing our data pessimistically. From the slope of this line, it is seen that during the time necessary for the collection of one ESDIAD pattern, the percentage change in the measured $\mathrm{O}^{+}$intensity and hence the ESD damage to chemisorbed $\mathrm{NO}$ is negligible $(<1 \%)$.

Fig. 27 presents a retarding-grid measurement of the normal kinetic energy distribution of $\mathrm{O}^{+}$ions desorbed via ESD from NO/Pd(111). After NO exposure $\left(1.6 \times 10^{15} \mathrm{~cm}^{-2}\right)$ at $300 \mathrm{~K}$, the crystal was cooled to $100 \mathrm{~K}$. ESDIAD patterns were then

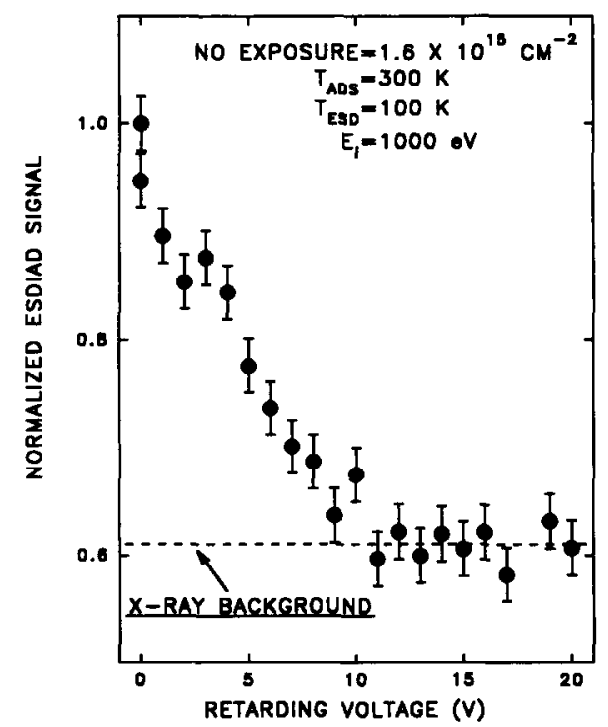

Fig. 27. The dependence of the signal observed during electron bombardment of $\mathrm{NO} / \mathrm{Pd}(111)$ on the retarding voltage (positive with respect to the crystal) applied to the inner retarding grid of the ESDIAD analyzer. The $\mathrm{O}^{+}$ions from adsorbed $\mathrm{NO}$ are completely retarded at $\sim 12 \mathrm{~V}$, leaving only the $\mathrm{X}$-ray background signal. An NO exposure of $1.6 \times 10^{15} \mathrm{~cm}^{-2}$ at $300 \mathrm{~K}$ was employed, and the electron energy was $1000 \mathrm{eV}$. The abscissa has not been corrected for differences in work function.

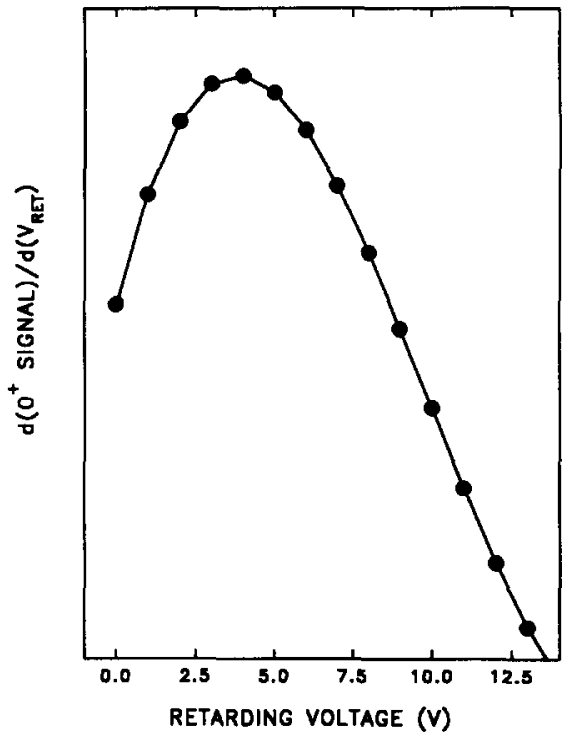

Fig. 28. Numerical derivative of a fourth-order polynomial fit to the data of Fig. 27. This curve, with a maximum near $3.9 \mathrm{~V}$ and an average HWHM of $5.1 \mathrm{~V}$, represents a measure of the normal kinetic energy distribution of the $\mathrm{O}^{+}$ions desorbed from NO/ $\operatorname{Pd}(111)$.

collected $\left(E_{\mathrm{i}}=1000 \mathrm{eV}, I=3.0 \mathrm{nA}\right)$ with the crystal grounded, but with a positive 'retarding potential' $\left(V_{\text {ret }}\right)$ placed on the third grid of the detection optics. This retarding voltage serves as the abscissa of Fig. 27 , and is uncorrected for work function differences.

As evident in Fig. 27, the integrated ESDIAD signal decreases with an increase in $V_{\text {ret }}$, leveling off at $\sim 12 \mathrm{~V}$. The dashed line in Fig. 27 indicates the relative magnitude of the $\mathrm{X}$-ray background (which is independent of $V_{\text {ret }}$ ) present in the ESDIAD patterns from NO/Pd before hackground subtraction. The measured $\mathrm{X}$-ray background from a metal surface is known to increase with $E_{\mathrm{i}}$ [6], however so does the $\mathrm{O}^{+}$intensity from adsorbed NO (see Fig. 25). The presence of these competing effects explains the diminished signal quality of the $\mathrm{O}^{+}$ESDIAD patterns presented in the main body of this paper, compared to other ESDIAD studies where the $\mathrm{X}$-ray background is smaller.

The data of Fig. 27 was fit to a fourth-order polynomial by a least-squares fitting routine. The derivative of the resulting function was calculated, and is plotted in Fig. 28 versus $V_{\text {ret }}$. It can be seen that the function in Fig. 28 is skewed, with a maxi- 
mum near $3.9 \mathrm{~V}$ and an average HWHM of about $5.1 \mathrm{~V}$. Although uncorrected for work function differences, the curve presented in Fig. 28 represents an estimate of the normal kinetic energy distribution of $\mathrm{O}^{+}$ions desorbed via ESD from NO/Pd(111).

\section{Acknowledgement}

The authors have benefitted from long discussions with Mr. Paul Pijpers, and gladly acknowledge his helpful suggestions. One of the authors (R.D.R.) acknowledges partial support from a Mellon Fellowship at the University of Pittsburgh.

\section{References}

[1] H.S. Taylor, Proc. R. Soc. London Ser. A 105 (1925) 108.

[2] See, for example: Chemistry in Two Dimensions: Surfaces, Ed. G.A. Somorjai (Cornell Univ. Press, Ithaca, NY, 1981).

[3] C.T. Campbell and S.M. Valone, J. Vac. Sci. Technol. A 3 (1985) 408.

[4] M.J. Bozack, L. Muehlhoff, J.N. Russell, Jr., W.J. Choyke and J.T. Yates, Jr., J. Vac. Sci. Technol. A 5 (1987) 1.

[5] A. Winkler and J.T. Yates, Jr., J. Vac. Sci. Technol. A 6 (1988) 2929.

[6] M.J. Dresser, M.D. Alvey and J.T. Yates, Jr., Surf. Sci. 169 (1986) 91; J. Vac. Sci. Technol. A 4 (1986) 1446.

[7] J.T. Yatcs, Jr., M.D. Alvcy, K.W. Kolasinski and M.J. Dresser, Nucl. Instr. Methods B 27 (1987) 147.

[8] P.J. Chen, M.L. Colaianni and J.T. Yates, Jr., J. Vac. Sci. Technol. A 8 (1990) 764.

[9] R.G. Musket, W. McLean, C.A. Colmenares, D.M. Makowiecki and W.J. Siekhaus, Appl. Surf. Sci. 10 (1982) 143 , and references therein.

[10] J.C. Tracy and P.W. Palmberg, J. Chem. Phys. 51 (1969) 4852.

[11] P.W. Davies and R.M. Lambert, Surf. Sci. 110 (1981) 227.

[12] J.C. Hamilton and J.M. Blakely, Surf. Sci. 91 (1980) 199.

[13] I. Ratajczykowa, J. Vac. Sci. Technol. A 1 (1983) 1512; Surf. Sci. 152/153 (1985) 627.

[14] R.D. Ramsier, Q. Gao, H. Neergaard Waltenburg and J.T. Yates, Jr., J. Chem. Phys. 100 (1994) 6837.

[15] J.B. Miller, H.R. Siddiqui, S.M. Gates, J.N. Russell, Jr., J.T. Yates, Jr., J.C. Tully and M.J. Cardillo, J. Chem. Phys. 87 (1987) 6725.

[16] Q. Gao, R.D. Ramsier, H. Neergaard Waltenburg and J.T. Yates, Jr., J. Am. Chem. Soc. 116 (1994) 3901.

[17] H. Conrad, G. Ertl, J. Küppers and E.E. Latta, Surf. Sci. 65 (1977) $235 ; 245$.

[18] H.-D. Schmick and H.-W. Wassmuth, Surf. Sci. 123 (1982) 471.
[19] E. Miyazaki, I. Kujina, M. Orita, K. Sawa, N. Sanada, T. Miyahara and H. Kato, Surf. Sci. 176 (1986) L841.

[20] E. Miyazaki, I. Kojima, M. Orita, K. Sawa, N. Sanada, K. Edamoto, T. Miyahara and H. Kato, J. Electron Spectrosc. Relat. Phenom. 43 (1987) 139.

[21] S. Sugai, H. Watanabe, H. Miki, T. Kioka and K. Kawasaki, Vacuum 41 (1990) 90.

[22] M. Bertolo and K. Jacobi, Surf. Sci. 236 (1990) 143; 226 (1990) 207.

[23] S. Sugai, H. Watanabe, T. Kioka, H. Miki and K. Kawasaki, Surf. Sci. 259 (1991) 109.

[24] D.T. Wickham, B.A. Banse and B.E. Kuel, Surf. Sci. 243 (1991) 83.

[25] X. Xu, P.J. Chen and D.W. Goodman, J. Phys. Chem., in press.

[26] R. Raval, M.A. Harrison, S. Haq and D.A. King, Surf. Sci. 294 (1993) 10.

[27] C. Nyberg and P. Uvdal, Surf. Sci. 204 (1988) 517; 211/212 (1989) 923.

[28] S.W. Jorgensen, N.D.S. Canning and R.J. Madix, Surf. Sci. 179 (1987) 322.

[29] J. Singh, W.K. Walter, A. Atrei and D.A. King, Chem. Phys. Lett. 185 (1991) 426.

[30] V.P. Zhdanov, Surf. Sci. 133 (1983) 469; 111 (1981) L662.

[31] J.W. Niemantsverdriet, K. Markert and K. Wandelt, Appl. Surf. Sci. 31 (1988) 211.

[32] J.W. Niemantsverdriet and K. Wandelt, J. Vac. Sci. Technol. A 6 (1988) 757.

[33] E.G. Seebauer, A.C.F. Kong and L.D. Schmidt, Surf. Sci. 193 (1988) 417.

[34] P.A. Redhead, Vacuum 12 (1962) 203.

[35] J.H. Enemark and R.D. Feltham, Coord. Chem. Rev. 13 (1974) 339;

G.B. Richter-Addo and P. Legzdins, Metal Nitrosyls (Oxford, New York, NY, 1992).

[36] M.E. Bartram, B.E. Koel and E.A. Carter, Surf. Sci. 219 (1989) 467.

[37] M.C. Asensio, D.P. Woodruff, A.W. Robinson, K.-M. Schindler, P. Gardner, D. Ricken, A.M. Bradshaw, J.C. Conesa and A.R. Gonzalez-Elipe, J. Vac. Sci. Technol. A 10 (1992) 2445; Chem. Phys. Lett. 192 (1992) 259.

[38] S. Aminpironz, A. Schmalz., I. Becker and J. Haase, Phys. Rev. B 45 (1992) 6337.

[39] N. Materer, A. Barbieri, D. Gardin, U. Starke, J.D. Batteas, M.A. Van Hove and G.A. Somorjai, Phys. Rev. B 48 (1993) 2859.

[40] B.A. Banse and B.E. Koel, Surf. Sci. 232 (1990) 275.

[41] R. Imbihl and J.E. Demuth, Surf. Sci. 173 (1986) 395.

[42] M. Milun, P. Dervan, M. Vajic and K. Wandelt, Surf. Sci. $211 / 212$ (1989) 887.

[43] J.-W. He, U. Memmert, K. Griffiths and P.R. Norton, J. Chem. Phys. 90 (1989) 5082.

[44] J.-W. He, U. Memmert and P.R. Norton, J. Chem. Phys. 90 (1989) 5088.

[45] See: H. Ibach and D.L. Mills, Electron Energy Loss Spectroscopy and Surface Vibrations (Academic Press, New York, NY, 1982) pp. 282-284, and references therein. 
[46] D. Alfe, P. Rudolf, M. Kiskinova and R. Rosei, Chem. Phys. Lett. 211 (1993) 220.

[47] S. Sugai, H. Yoshikawa, H. Miki, T. Kioka and K. Kawasaki, Appl. Surf. Sci. 33/34 (1988) 301.

[48] M. Nishijima, K. Fujiwara and T. Murotani, J. Appl. Phys. 46 (1975) 3089.

[49] E.C. Ekwelundu and A. Ignatiev, Surf. Sci. 215 (1989) 91.

[50] F.P. Netzer and T.E. Madey, Surf. Sci. 110 (1981) 251.

[51] F. Bozso and Ph. Avouris, Chem. Phys. Lett. 125 (1986) 531.

[52] R. Jaeger, R. Treichler and J. Stohr, Surf. Sci. 117 (1982) 533.

[53] A. Takano and K. Ueda, Surf. Sci. 287/288 (1993) 25.

[54] A.R. Burns, Phys. Rev. Lett. 55 (1985) 525.

[55] U. Schwalke, H. Niehus and G. Comsa, in: Desorption Induced by Electronic Transitions (DIET II), Eds. W. Brenig and D. Menzel (Springer, Berlin, 1985) p. 98; Surf. Sci. 137 (1984) 23.

[56] A. Szabo, M.A. Henderson and J.T. Yates, Jr., J. Chem. Phys. 92 (1990) 2208.

[57] A.R. Burns, E.B. Stechel and D.R. Jennison, Surf. Sci. 280 (1993) 359.

[58] U. Heiz, J. Xu and J.T. Yates, Jr., J. Chem. Phys. 100 (1994) 3925 ;

U. Heiz, J. Xu, J.W. Gadzuk and J.T. Yates, Jr., J. Chem. Phys. 101 (1994) 4373.
[59] R.D. Ramsier and J.T. Yates, Jr., Surf. Sci. Rep. 12 (1991) 243, and references therein;

J.T. Yates, Jr., M.D. Alvey, M.J. Dresser, M.A. Henderson, M. Kiskinova, R.D. Ramsier and A. Szabo, Science 255 (1992) 1397.

[60] W.L. Clinton, M.A. Esrick and W.S. Sacks, Phys. Rev. B 31 (1985) 7540; 7550.

[61] Z. Miskovic, J. Vukanic and T.E. Madey, Surf. Sci. 141 (1984) $285 ; 169$ (1986) 405.

[62] W. Jelend and D. Menzel, Surf. Sci. 40 (1973) 295; 42 (1974) 485.

[63] T.E. Madey, Surf. Sci. 94 (1980) 483.

[64] E.B. Stechel and M.L. Knotek, Surf. Sci. 167 (1986) 297; F.P. Netzer and T.E. Madey, J. Chem. Phys. 76 (1982) 710.

[65] R. Smoluchowski, Phys. Rev. 60 (1941) 661.

[66] B. Krahl-Urban, H. Wagner and R. Butz, Surf. Sci. 93 (1980) 423.

[67] W.L. Clinton, M. Esrick, H. Ruf and W. Sacks, Phys. Rev. B 31 (1985) 722.

[68] J. Tersoff and L.M. Falicov, Phys. Rev. B 24 (1981) 754.

[69] Y. Hasegawa and Ph. Avouris, Phys. Rev. Lett. 71 (1993) 1071;

M.F. Crommie, C.P. Lutz and D.M. Eigler, Nature (London) 363 (1993) 524.

[70] J.T. Yates, Jr. and D.A. King, J. Vac. Sci. Technol. 9 (1972) 1256. 